\title{
Informação como objeto de estudo: histórico da pós-graduação em Ciência da Informação na Universidade de Brasília
}

\author{
Kira Tarapanoff \\ Universidade de Brasília, Faculdade de Ciência da Informação, Brasília, DF, \\ Brasil \\ ktarapanoff@gmail.com \\ Lillian Alvares \\ Universidade de Brasília, Faculdade de Ciência da Informação, Brasília, DF, \\ Brasil \\ lillianalvarres@unb.br
}

DOI: https://doi.org/10.26512/rici.v12.n1.2019.19163

Recebido/Aceptado/Received: 2018-11-12

Aceitado/Aceptado/Accepted: 2018-11-14

Resumo: Descreve o contexto, criação e a trajetória dos cursos de pós-graduação da atual Faculdade de Ciência da Informação da Universidade de Brasília. Na gênese e histórico da criação de seu Mestrado em Biblioteconomia e Documentação, detém-se nas principais linhas de pesquisa que orientaram o desenvolvimento de suas dissertações, com destaque para alguns trabalhos. Em sua evolução, descreve a criação do Doutorado e a integração das várias áreas que tem como objeto de estudo a informação, como a Biblioteconomia, Arquivologia e Museologia, colocadas sob um mesmo guarda chuva de pósgraduação em Ciência da Informação. Analisa quantitativamente o período de 2006 a 2018, visualizando as temáticas de pesquisa e defesas realizadas do nível de mestrado e doutorado. Como considerações finais, enfatiza que é preciso levar em conta as mudanças tecnológicas e culturais contínuas na sociedade. Para tanto, será necessário integrar-se e antecipar de forma adequada e contínua às novas necessidades informacionais de usuários e organizações.

Palavras-Chave: teses e dissertações. mestrado. doutorado. Biblioteconomia. Arquivologia. Museologia. pesquisa.

Information as object of study: history of the post graduate courses in Information Science of the University of Brasilia

\begin{abstract}
Describes the context, creation and trajectory of the post-graduate courses of the University of Brasilia's Faculty of Information Science. Describes the main research lines which guided its first post graduate course at Master level, since its genesis and throughout its history, with some examples. From the Master experience and its consolidation, the Doctorate in Information Science Program was created, integrating the areas of Librarianship, Archival Science, and Museology, under the same umbrella of post-graduate studies in Information Science. Analyses quantitatively the production of the theses and dissertations, between 2006 and 2018, in a thematic form. Considering continuous technological and cultural changes in society it will be necessary to integrate and anticipate adequately the information needs and demands of users and organizations in Brazil.
\end{abstract}

Keywords: theses. dissertations. master degree. doctoral degree. Librarianship. Archival Science. Museology. research. 


\section{Información como objeto de estudio: historia de los cursos de postgrado en Ciencias de la Información de la Universidad de Brasilia}

Resumen: Describe el contexto, creación y trayectoria de los cursos de postgrado de la actual Facultad de Ciencia de la Información de la Universidad de Brasilia. En la génesis e histórico de la creación de su Maestría en Biblioteconomía y Documentación, se detiene en las principales líneas de investigación que orientaron el desarrollo de sus disertaciones, con destaque para algunos trabajos. En su evolución, describe la creación del Doctorado y la integración de las varias áreas que tienen como objeto de estudio la información, como la Biblioteconomía, Archivología y Museología, colocadas bajo un mismo paraguas de postgrado en Ciencia de la Información. Analiza cuantitativamente el período de 2006 a 2018, con vistas sobre temáticas de investigación y defensas realizadas en su maestría y doctorado. Concluye la necesidad de anticipar e integrar de forma continua y adecuada a las nuevas necesidades informacionales de usuarios y organizaciones, frente a los cambios tecnológicos y culturales de la sociedad.

Palabras-clave: Archivología. Biblioteconomía. doctorado. maestría. Museología. investigación. Universidad de Brasilia.

\section{Antecedentes e contextualização}

Vencedor do concurso ${ }^{1}$ para a construção da nova capital do Brasil no Planalto Central, Brasília $^{2}$, o urbanista Lúcio Costa, em seu projeto para o Plano Piloto, previu a construção de uma universidade. Segundo o urbanista, seria um erro se a nova capital fosse concebida apenas como urbs (zona de habitação) e não como civitas (conjunto de cidadãos). Deveria ser também um centro de nucleação e irradiação de cultura. Em seu projeto uma ampla área de 257 hectares na Asa Norte da cidade, junto ao Lago, seria destinada para este propósito.

No dia da inauguração de Brasília3 , em 21 de abril de 1960, o Presidente da República, Juscelino Kubitschek de Oliveira (1956-1961) encaminhou ao Congresso Nacional o projeto de sua criação, entregando nas mãos de Anísio Teixeira o planejamento da educação para o novo Distrito Federal. Inspirado na teoria pedagógica de John Dewey (1959), Teixeira acreditava no ideal educativo e social do crescimento contínuo dos indivíduos, ou seja, no ser humano destinado a uma formação durante toda a vida ${ }^{4}$. Na filosofia de Dewey sugere-se um modelo

\footnotetext{
${ }^{1}$ Ocorrido entre setembro de 1956 e março de 1957.

2Chamada por André Malraux (Ministro de Assuntos Culturais da França) de "a capital da esperança", em seu discurso proferido em 25 de agosto de 1959 em Brasília (BRAGA, 2010)

${ }^{3}$ José Bonifácio de Andrada e Silva (Patriarca da Independência), em 1825, propõe a transferência da capital (Rio de Janeiro) para Goiás e sugere o nome de Brasília (COSTA, 1957).

${ }^{4} \mathrm{O}$ modelo educacional projetado por Anísio Teixeira enfatizou a continuidade entre escola e universidade, bem como a constituição de um novo pensamento pedagógico, inspirado nas ideias de John Dewey, a de formar "cérebros" criativos e autônomos, sem distinção entre filhos de trabalhadores e filhos das elites. $O$ sistema de ensino proposto incluía as seguintes instituições escolares: a) Centros de Educação Elementar, integrados por Jardins de Infância, Escolas-Classe e Escolas-Parque; b) Centros de Educação Média, destinados à Escola Secundária Abrangente e ao Parque de Educação Média; c) Universidade de Brasília, composta de Institutos, Faculdades e demais dependências destinadas à administração, biblioteca, campos de recreação e desportos (TEIXEIRA, 1961). Seu modelo educacional público foi efetivamente implantado em 1960, com a criação dos: Centro de Ensino Fundamental (CASEB), Centro Educacional Elefante Branco (CEEB), Escolas Classe (recreação e artes), Centro Integrado de Ensino Médio (CIEM) e a da própria Universidade de Brasília (UnB).
} 
educacional, que prioriza o aspecto natural do homem e desenvolve nele a capacidade lógica de pensar o mundo e agir sobre ele. O homem deve ser educado para que, junto com o meio, que modifica, se transforme constantemente (ALI, 2014).

Ao planejamento da Universidade de Brasília (UnB), outros nomes se somaram: Vitor Nunes Leal e Cyro dos Anjos, respectivamente chefe e subchefe da Casa Civil de JK, Lúcio Costa e Oscar Niemeyer ${ }^{5}$. Juntos com Darcy Ribeiro ${ }^{6}$ foram nomeados como responsáveis pela criação da UnB (MIGLIEVICH-RIBEIRO, 2017).

Visualizavam eles criar uma universidade tão inovadora no plano cultural e social quanto o era a nova capital no plano urbanístico e arquitetônico. Embora o Presidente tenha apresentado ao Congresso Nacional o Projeto de Lei para criação da Fundação Universidade de Brasília (FUB) em 21 de abril de 1960, sua aprovação se deu só em 25 de agosto de 1961, no dia da renúncia do presidente Jânio Quadros ${ }^{7}$, em meio à perplexidade da Casa e por uma rápida e estratégica mudança na Ordem do Dia. Em 15 de dezembro de 1961 a Lei 3.998, que autoriza a fundação da UnB, é assinada pelo presidente João Goulart (1961-1964) ${ }^{8}$, nomeando Darcy Ribeiro ${ }^{9}$ e Anísio Teixeira para os cargos de reitor e vice-reitor, respectivamente.

Inaugurada em 21 de abril de 1962, a universidade começou a funcionar imediatamente. Seus principais objetivos eram o desenvolvimento de uma cultura e de uma tecnologia nacionais, ligadas ao projeto desenvolvimentista. Sua estrutura era integrada, flexível e moderna contrapondo-se à universidade segmentada em cursos de formação profissional. Seguindo o modelo norte-americano, organizou-se na forma de fundação, sendo que os departamentos vieram substituir as cátedras. Com uma estrutura curricular inovadora e a presença de reputados profissionais e educadores nacionais ${ }^{10}$, a vida acadêmica floresceu nos anos que se seguiram até a intervenção militar desencadeada no país, em 31 de março de $1964^{11}$.

Tendo idealizado uma universidade, não "reprodutiva"12, que pudesse realmente interferir no desenvolvimento econômico e social do país, seus criadores incentivaram a interdisciplinaridade e a pesquisa científica. Visavam uma instituição onde professores e alunos, por meio de atividades de ensino, pesquisa e extensão se engajassem no planejamento social, tornando-se aptos a antecipar transformações do contexto social, e podendo nele

${ }^{5}$ Oscar Niemeyer foi o arquiteto encarregado da concepção arquitetônica de Brasília e de seus edifícios cívicos.

6 No breve governo de Jânio Quadros, Darcy Ribeiro é confirmado, por Decreto, na qualidade de coordenador de planejamento da Universidade de Brasília.

7 Jânio Quadros se manteve no governo apenas de 31 de janeiro de 1961 a 25 de agosto de 1961, data em que renunciou.

8 João Goulart era vice-presidente de Jânio Quadros e o substituiu legalmente na presidência após renúncia.

${ }^{9} \mathrm{O}$ primeiro período frente à Reitoria Darcy Ribeiro foi de 4 de janeiro de 1962 a 19 de setembro de 1962, sendo substituído pelo Frei Matheus Rocha (19 de setembro de 1962 a 24 de janeiro de 1963). Darcy Ribeiro volta, por mais um breve período (19 de setembro de 1962 a 24 de janeiro de 1963) .

10“Eram mais de duzentos sábios e aprendizes, selecionados por seu talento para plantar aqui a sabedoria humana", escreveu Darcy Ribeiro, em A Invenção da Universidade de Brasília (1995).

${ }^{11}$ Os principais elementos deflagradores do golpe tinham natureza política: o medo, a insegurança e a reação ao processo de "esquerdização" ou de "comunização" supostamente em curso no país.

${ }^{12}$ Bourdieu e Passeron em sua obra "A reprodução" (1970) buscaram evidências para mostrar que a escola e todo o sistema de ensino existem como ferramenta de manutenção dos paradigmas sociais estabelecidos, passando por cima ou excluindo os diferentes e neutralizando as diferenças. 
intervir e provocar mudanças (MIGLIEVICH-RIBEIRO, 2017). Contudo, essa visão proposta foi considerada subversiva ${ }^{13}$ pelo governo de ditadura militar ${ }^{14}$, que pretendia "varrer" as ideias revolucionárias do país ${ }^{15}$.

Em 9 de abril de 1964, militares invadem o campus em busca de armas e material de propaganda considerado subversivo. Um inquérito Policial Militar é instaurado contra professores e estudantes por denúncias de subversão e indisciplina na universidade. Nos dias que se seguem, o regime militar extingue o mandato do reitor Anísio Teixeira ${ }^{16}$. Em seu lugar é nomeado o médico Zeferino $\mathrm{Vaz}^{17}$, que afasta 15 docentes. A interferência de autoridades do governo na universidade continua, e entre junho e setembro de 1965 a crise torna-se mais aguda, quando vários alunos são expulsos. Zeferino Vaz, após uma audiência com o presidente militar Castello Branco, anuncia sua renúncia.

O novo reitor empossado, Laerte Ramos de Carvalho ${ }^{18}$, professor da USP, suspende as atividades acadêmicas e solicita ao DOPS ${ }^{19}$ o envio de tropas policiais ao campus e quinze professores são demitidos. A comunidade universitária reage, mas o diálogo é suspenso pelo reitor, deflagrando, como consequência, a demissão voluntária de 223 professores ${ }^{20}$ na maior diáspora da história das universidades brasileiras. Neste momento, de uma só vez, a universidade perde o equivalente a $79 \%$ de seus docentes à época. Os estudantes, ainda que fatalmente prejudicados, dão irrestrito apoio a seus mestres. Essa demissão coletiva, talvez caso único na história da universidade no mundo, foi espontânea, não foi programada, nem dirigida do Exterior como alguns pretenderam (SALMERON, 2012).

A oposição de alunos e professores da Universidade continuou forte à ditadura militar e, em 29 de agosto de 1968, o campus sofre violenta invasão. Policiais civis, militares, do DOPS e Exército, com armas em punho, perseguem estudantes por toda a universidade. Cerca de 500 alunos são detidos, sendo 60 presos, dentre eles, o líder estudantil Honestino Guimarães, posteriormente desaparecido.

Após o mandato de Laerte Ramos de Carvalho, na vigência do período militar, foram reitores da UnB, os professores: Caio Benjamin Dias (1967-1971); Amadeu Cury (1967-1971); e José Carlos de Almeida Azevedo (1976-1985). Em 1977, estudantes e professores fazem protesto pedindo a demissão do reitor Azevedo. Nesta ocasião são suspensos dezesseis alunos identificados como líderes das manifestações. Este fato motivou a decisão dos estudantes a entrar em greve por tempo indeterminado. Em represália, o reitor solicita a presença da Polícia Militar (PM), que ocupa o campus e força o reinício das aulas. Nesse ano, o campus

13Seu principal idealizador Anísio Teixeira, já na sua anterior proposta em relação à Universidade do Distrito Federal (UDF), no Rio de Janeiro, em 1935, amealhou críticos e passou a ser duramente perseguido pelo regime ditatorial de Getúlio Vargas e pela igreja, que o acusava de comunista. Exilou-se à época em sua terra natal, a Bahia (CAITANO, 2012, p.14).

${ }^{14}$ Humberto de Alencar Castelo Branco foi o primeiro presidente da Ditadura Militar instaurada no Brasil em 1964, seu mandato teve vigência de 15 de abril de 1964 - 15 de março de 1967.

${ }^{15}$ As representações anticomunistas, que foram dominantes nos discursos favoráveis ao golpe, expressavam o temor em relação aos movimentos sociais no campo [...] à força crescente dos sindicatos [...], à politização dos subalternos das Forças Armadas e à 'esquerdização' dos jovens universitários (MOTTA, 2014, p. 23).

${ }^{16}$ Reitor de 19 de junho de 1963 a 9 de abril de 1964.

17 Reitor nomeado pró tempore (9 de abril de 1964 a 25 de agosto de 1965) em substituição a Anísio Teixeira, afastado pelo regime militar.

18 Nomeado pelo governo militar esteve à frente da reitoria de 25 de agosto de 1965 a 3 de novembro de 1967.

19 Departamento de Ordem Política e Social (DOPS), criado em 30 de dezembro de 1924, foi o órgão do governo brasileiro utilizado principalmente durante o Estado Novo e na Ditadura Militar.

20 "Eram mais de duzentos sábios e aprendizes, selecionados por seu talento para plantar aqui a sabedoria humana", escreveu Darcy Ribeiro, em A Invenção da Universidade de Brasília. 
ainda seria ocupado duas outras vezes pela PM. Em 1979, foi criada a Lei no 6.733/79, que permite que o reitor e vice-reitor das universidades federais passam a ser escolhidos pelo presidente da República, sem a exigência da anterior lista sêxtupla. Os cargos de direção passam a ser de confiança, nomeados diretamente pelo reitor. A Lei é apelidada de "Lei Azevedo", porque esvaziou a crescente oposição ao então reitor da UnB, permitindo que ele seguisse no cargo até 12 de março de 1985, ano que marca o período civil democrático, vigente até os dias atuais.

Após uma transição política negociada para a posse do governo civil, e a votação do Colégio Eleitoral ${ }^{21}$, realizada em 15 de janeiro de 1985, foi escolhido para Presidente do Brasil - Tancredo Neves, que veio a falecer antes de tomar posse. Foi substituído por seu vice de chapa José Sarney, que assumiu a presidência em 21 de abril de 1985, permanecendo no cargo até 15 de março de 1990. Sarney sucedeu ao último presidente do período militar - João Figueiredo (1979-1985).

A partir de 1985, os reitores da UnB passaram a ser escolhidos pela comunidade acadêmica. O primeiro reitor escolhido por eleição direta foi o professor Cristóvão Buarque (1985-1989). O reitor que o sucedeu, escolhido em eleição direta, foi Antônio Ibañez Ruiz (1989-1993); sucedido pelos professores: João Claudio Todorov (1993-1997); Lauro Morhy (1997-2005); Timothy Mulholland (2005-2008); José Geraldo de Sousa Junior (2008-2012); Ivan Camargo (2012-2016); e Márcia Abrahão (24.11.2016 -).

Hoje, a Universidade de Brasília (UnB) é considerada pelo ranking oficial de universidades brasileiras, como uma das melhores, apresentando uma produção científica representativa. Este trabalho refere-se à produção da Pós Graduação da Faculdade de Ciência da Informação, desde sua criação até os dias atuais.

\section{Pós-Graduação em Biblioteconomia e Documentação}

\subsection{Faculdade de Biblioteconomia}

Foi nesse contexto que nasce a Faculdade de Biblioteconomia prevista já no Plano Orientador de 1962. A ideia original era formar bibliotecários, em nível de Mestrado, atraindo alunos graduados egressos dos Institutos Centrais de Ciências, Letras e Artes, no sentido de prosseguirem no curso de pós-graduação em Biblioteconomia, destinados à formação de bibliotecários especializados ${ }^{22}$, seguindo o modelo americano, nas várias áreas do saber.

Centrados no resgate da produção científica brasileira, os professores Rubens Borba de Moraes $^{23}$, Abner Lellis Correa Vicentini ${ }^{24}$, Astério Tavares Campos ${ }^{25}$, Zeferino Pereira Paulo ${ }^{26} \mathrm{e}$

\footnotetext{
${ }^{21}$ A eleição presidencial brasileira de 1985 foi a última ocorrida de forma indireta, por meio de um colégio eleitoral, sob a égide da Constituição de 1967.
}

\footnotetext{
22`Na Biblioteca Central funcionará o curso de Biblioteconomia, montado para receber alunos bacharelados pelos Institutos Centrais e especializá-los na biblioteconomia e documentação nos respectivos campos de especialidades' (RIBEIRO, 2012. p.27).

${ }^{23} \mathrm{O}$ pesquisador e bibliófilo - Rubens Borba de Moraes organizou e publicou bibliografias brasileiras essenciais, como a "Bibliographia brasiliana: a bibliographical essay on rare books on Brazil published from 1504 to 1900 and works of Brazilian authors published abroad before the independence of Brazil in 1822". Rio de Janeiro: Calibris, 1958; e a "Bibliografia brasileira do período colonial: catálogo comentado das obras dos autores nascidos no Brasil e publicado antes de 1808". São Paulo: Instituto de Estudos
} 
Edson Nery da Fonseca, este último seu Diretor, criaram o Mestrado em Bibliografia Brasileira ${ }^{27}$, experiência pioneira na área que funcionou de março de 1964 a dezembro de 1965, quando foi interrompido pela diáspora docente na UnB.

Disciplinas iniciais incluíam Bibliografia Brasileira, ministrada pelo Prof. Rubens Borba de Moraes; Indexação em Cadeia, pelo Prof. Abner Lellis Correia Vicentini; Organização do Trabalho Intelectual, pelo Prof. Astério Tavares Campos, além de Normalização e Documentação Científica pelo Prof. Zeferino Ferreira Paulo.

Deste curso pioneiro participaram apenas três alunas: Zila Mamede, da Universidade do Rio Grande do Norte; Gilda Verri, que trabalhava então na Comissão de Desenvolvimento Econômico de Pernambuco (Codepe); e Fernanda Leite Ribeiro, do Instituto Brasileiro de Bibliografia e Documentação (IBBD), que cursou apenas o primeiro ano afastando-se para terminar o Mestrado na Universidade de Pittsburgh nos Estados Unidos.

Embora o curso tenha sido bruscamente interrompido e suas alunas não tenham terminado seu Mestrado, Zila Mamede elaborou a 'Bibliografia de Câmara Cascudo'28, Gilda Verri, preparou e publicou a bibliografia 'Viajantes Franceses no Brasil'29; e Fernanda Leite Ribeiro desenvolveu a bibliografia de Rui Barbosa pela Universidade de Brasília (Ruiana) ${ }^{30}$.

\subsection{Departamento de Biblioteconomia e Documentação}

O Mestrado em Bibliografia Brasileira, encerrado em dezembro de 1965, retorna como curso de Biblioteconomia ${ }^{31}$ em nível de Bacharelado em 1965. Seu currículo pleno incorporou, desde logo, uma formação técnica, ligada às atividades da documentação, que focalizava, de forma pioneira no Brasil, a incipiente mecanização e automação de bibliotecas (UNIVERSIDADE DE BRASÍLIA, 2005).

Brasileiros/USP, 1969; e, juntamente com Ana Maria Camargo, a "Bibliografia da Impressão Régia do Rio de Janeiro". São Paulo: EDUSP, 1993, 2 v.

${ }^{24}$ O Prof. Vicentini foi coordenador da Biblioteca Central da Universidade de Brasília (de 1964 a 1968), tendo sido também Professor na Faculdade de Biblioteconomia. Foi dos primeiros a divulgar a Documentação, a Classificação Universal, a automação e também a recém criada (1967) Ciência da Informação, tratada na obra do russo Alexander Mikhailov, com o nome de "Informatika" (CUNHA, 2013, p. 49 ).

25 O Prof. Astério formou-se em Filosofia e Teologia e foi Doutor em Direito Canônico. Um grande estudioso das classificações Bibliográficas, em especial da CDU.

${ }^{26}$ O Prof. Zeferino Paulo veio da Associação Portuguesa de Normalização Técnica, especialista em documentação e normas, atuou pela criação da comissão de Documentação na Associação Brasileira de Normas Técnicas (ABNT).

${ }^{27}$ A Bibliografia, produto da Documentação, ganhou espaço em estudos na França, conceituada como a ciência que se propõe a buscar, identificar, descrever e classificar documentos impressos, com o fim de construir repertórios adequados para facilitar o trabalho intelectual (MALCLÈS, 1973).

28 MAMEDE, Z. Bibliografia anotada Luís da Câmara Cascudo: 50 anos de vida intelectual 1918/1968. Natal: Fundação João Augusto, 1970.

${ }^{29}$ VERRI, G. M. W. Viajantes franceses no Brasil. Recife: Editora Universitária da UFPE, 1994.

${ }^{30}$ RIBEIRO, F. L. Ruiana na Universidade de Brasília: catálogo da seção de Rui Barbosa da coleção Homero Pires. Publicada no Rio de janeiro pela Casa Rui Barbosa, em 1967.

${ }^{31}$ O curso de Biblioteconomia da UnB foi reconhecido em 30 de junho de 1969 (Portaria 064745). 
Os meios automáticos começaram a ser associados ao tratamento da informação, revolucionando os processos até então usados e fizeram surgir novas abordagens em relação aos documentos, sobretudo dirigidas aos conteúdos informativos. Neste período a informação já havia ganhado status de recurso indispensável para a investigação e o desenvolvimento (ARAÚJO, 2014).

Quanto à estrutura curricular, a UnB, seguiu a experiência estadunidense pautada em sistema de créditos. Esse sistema permitia o conhecimento compartilhado por todas as unidades universitárias, bem como facilitava a mobilidade dos discentes pelas disciplinas oferecidas.

É de se notar o crescente interesse pela disciplina Documentação, cujo objeto de estudo - o documento - incluía a totalidade dos artefatos humanos, registrados das mais diversas maneiras, nos mais diversos suportes: livros, manuscritos, fotografias, pinturas, esculturas, imagens em movimento, registros fonográficos, selos, estampas, etc. (OTLET, 1934). Na língua portuguesa, seu correlato, Documentologia significa "sistematização de técnicas de organização que objetivam a pesquisa, reunião e classificação de documentos de uma determinada área do conhecimento, usado pela museologia, discografia, arquivologia, etc." (HOUAISS, 2001).

Práticas documentárias começaram a se delinear com os trabalhos de Otlet e La Fontaine, que sistematizaram os conceitos de documentação a partir de estudos bibliográficos. Diferente da Biblioteconomia, muito voltada para o acesso e a função educacional, a Documentação tinha a função de acompanhar o documento desde sua gênese, ou seja, da produção de seu escritor até o momento de seu uso pelo leitor (OTLET, 1997).

Mais do que ter um documento, interessava aos pesquisadores envolvidos com a documentação promover uma listagem, um registro "onde" poderia estar cada um dos documentos produzidos pelo homem, o que foi enormemente facilitado pelas tecnologias da informação.

A disciplina Documentação foi para os arquivos, museus, centros de cultura e demais instituições que custodiavam registros humanos, aquilo que a Bibliografia tinha sido para a Biblioteconomia (ARAÚJO, 2014). Este entendimento abriu a possibilidade futura de uma integração da Biblioteconomia com as áreas de Arquivologia e Museologia.

\subsection{Mestrado em Biblioteconomia e Documentação}

Passado o período de 1962 a 1966 como Faculdade de Biblioteconomia, e de 1966 a 1970 como Faculdade de Biblioteconomia e Informação Científica (FBIC), a partir de 1970, com status de Departamento de Biblioteconomia e Documentação, ligado à Faculdade de Estudos Sociais Aplicados ${ }^{32}$, foi criado o Mestrado em Biblioteconomia e Documentação, em 1978.

Para o desenvolvimento do seu currículo foi convidada a Profa. Nice Menezes de Figueiredo, primeira profissional bibliotecária brasileira a obter o seu doutorado (PhD) na área $^{33}$. No desenvolvimento do currículo do Mestrado, a professora, inspirou-se nos ensinamentos de Dewey e também na Escola de Chicago, que serviu como parâmetro de

\footnotetext{
${ }^{32}$ Criada em 1970, congregava os Departamentos de Comunicação, Direito, e Biblioteconomia e Documentação.

${ }^{33}$ Sua tese de doutorado versava sobre "A conceptual methodology for error prevention in reference work", que focou no refinamento da questão na busca informacional em bases de dados, orientada pelo cientista da informação Gerald Jahoda da Florida State University, em Talahassee, EUA.
} 
excelência, por ter sido a primeira Graduate Library School, a criar o seu Doutorado, em 1926. Esta escola gerou importantes conceitos teóricos ${ }^{34}$, como o da Epistemologia Social ${ }^{35}$, que estuda o papel social do conhecimento. Isto é, as interações entre os processos intelectuais (conhecimento produzido) e as atividades sociais.

Duas áreas de concentração foram delineadas para as atividades de ensino pesquisa e extensão do mestrado implantado: (i) Planejamento, Organização e Administração de Sistemas de Informação, e (ii) Recursos e Técnicas de Documentação e Informação Especializada. A primeira área de concentração era voltada para a formação de gestores, enquanto a segunda visava atrair pessoas de várias áreas interessadas em tratamento de informação especializada.

\subsubsection{Planejamento, Organização e Administração de Sistemas de Informação}

Esta área levou em conta os ensinamentos da Escola de Chicago e a tradição da Biblioteconomia que incluíam a dimensão social da informação, sua vinculação com as práticas pedagógicas e literárias e seu papel na promoção da cultura (ARAÚJO, 2011). Ofereceu duas abordagens para o seu estudo - a sociocultural e a abordagem centrada no usuário.

A abordagem sociocultural enfatiza a sociedade e a cultura como requisitas para a informação se tornar significativa e relevante, justificando sua própria existência (BOELL, 2017).

A abordagem centrada no usuário leva em conta o fato de que a informação além de dependente do seu contexto sociocultural, também depende do indivíduo (usuário) (TABAK, 2014). Considera o "significado" (meaning), atribuído pelo usuário. Isto é, algo não só inerente à mensagem, mas algo que é dado pelo receptor (usuário), ou a mudança no conhecimento do indivíduo, relevante para uma situação específica. Por exemplo, a solução de um problema (BOELL, 2017).

Com essas orientações a informação pôde ser definida como "estrutura significante, capaz de gerar conhecimento no indivíduo, em seu grupo, ou na sociedade" (BARRETO, 1996, p. 407).

As primeiras dissertações do curso de Mestrado foram defendidas em 1980. No início, bastante calcadas nas funções biblioteconômicas (perfil do bibliotecário, biblioteca pública, etc.). No entanto, já no seu início, os interesses dos alunos e professores diversificaram-se também no sentido de incorporar temáticas de interesse da Ciência da Informação. Pesquisas relacionadas à informação científica e tecnológica, representação e recuperação informacional, estudos de usuários, gestão da informação nas organizações, economia política da informação, estudos métricos, quantitativos e estatísticos da informação, começaram a aparecer.

Para dar apenas um exemplo, dentre os estudos métricos ${ }^{36}$ da informação destacou-se primeiramente a bibliometria, que estuda aspectos quantitativos da produção, disseminação e uso da informação, utilizando-se de modelos matemáticos e estatísticos (por exemplo, as leis

\footnotetext{
${ }^{34}$ Ver Pierce Butler, An introduction to library science. Chicago: University of Chicago, 1933.

${ }^{35}$ Estuda os meios pelos quais o conhecimento é coordenado e integrado dentro de uma organização social complexa. Existe uma afinidade muito grande entre esta disciplina e a Biblioteconomia, já que a última é baseada em fundamentos epistemológicos e tem por objetivo aumentar a utilidade social dos registros gráficos, sendo fundamentalmente, a gerência do conhecimento (SHERA, 1977, p. 9).

36Métodos de pesquisa bibliométricos (análise de co-citação e acoplamento bibliográfico) são utilizados também em pesquisas cientométricas da comunicação acadêmica para mapear a exportação e importação do conhecimento e congêneres.
} 
de Bradford, de Lotka e de Zipf $\left.{ }^{37}\right)$. Nesta frente de pesquisa, dentre as primeiras dissertações defendidas no Mestrado de Biblioteconomia em 1980, pode-se mencionar o trabalho de Maria José da Fonseca Maia sobre a Unicidade da Lei de Bradford ${ }^{38}$ orientada pela Profa. Nice Menezes de Figueiredo.

\subsubsection{Recursos e Técnicas de Documentação e Informação Especializada}

Voltada para aspectos técnicos da documentação (organização de documentos, classificação, elaboração de tesauros, terminologias, etc.), esta área visava atrair interessados de outras áreas, que não somente da Biblioteconomia, para o tratamento informacional em diversas áreas do conhecimento, utilizando suas técnicas. Neste caso, surgiram estudos em interface com áreas as mais diversas, entre elas a Linguística.

Dentre os trabalhos desenvolvidos nesta linha de pesquisa destaca-se a terminologia, como importante área de interesse para a informação especializada, além de construção de sistemas de classificação do conhecimento, tesauros e ontologias. Conceituada como

\footnotetext{
"campo de estudos de caráter inter e transdisciplinar, o que a leva a convocar um conjunto de saberes para a apreensão do fenômeno terminológico, por excelência, o termo, cuja essência situa-se na representação lexical do conhecimento especializado e na sua divulgação. Para tanto, contribuem determinados conhecimentos exteriores e mesmo interiores aos estudos da linguagem" (KRIEGER; FINATO, 2004, p. 40).
}

Dentre as dissertações sobre terminologias, destacam-se os trabalhos de Marisa Brascher Basílio Medeiros, Levantamento e análise da terminologia brasileira em ciência da informação, aprovada em 1985; e de Lígia Café de Miranda sobre Terminologia de informática em língua portuguesa; contribuição para uma linguagem documentária integrada (Brasil e Portugal), aprovada em 1988, ambas sob a orientação do Prof. Ulf G. Baranow.

\subsection{Linhas de Pesquisa}

Já se notava dentre as dissertações defendidas no Mestrado e nas áreas de interesse dos professores orientadores que havia um crescente interesse com aspectos da Biblioteconomia e da Documentação, que extrapolavam os limites custodiais próprios dessas áreas, em especial devido às facilidades que a informática e a automação ofereciam, como por exemplo, a recuperação (automática) da informação ${ }^{39}$.

\footnotetext{
37A Lei de Bradford trata sobre a produtividade dos periódicos e permite fazer a estimativa do grau de relevância de revistas em uma determinada área do saber. A Lei de Lotka pode ser vista com uma função de probabilidade da produtividade. Quanto mais se publica, mais parece que se facilita publicar um novo trabalho e os pesquisadores que publicam resultados mais interessantes ganham mais reconhecimento e acesso a recursos para melhorar sua pesquisa. A Lei de Zipf é também conhecida como Lei do Menor Esforço e incide na medição de frequência do aparecimento das palavras em vários textos. Assim, é gerada uma lista ordenada de termos de uma determinada disciplina ou assunto.

38 Este trabalho demonstra que dividindo uma coleção de periódicos que publicam artigos sobre determinado assunto em classes de produtividade crescente, o $\mathrm{R}(\mathrm{nk})$ (total cumulativo de artigos em cada classe) satisfaz uma lei logarítmica que descreve uma curva ascendente que se torna uma linha reta para valores altos de k, como a encontrada por Bradford na sua verificação experimental. A expressão de R(nk) deduzida decorre da formulação verbal de Bradford. Portanto, é correto afirmar que a Lei de Bradford é uma só.

${ }^{39}$ Termo cunhado por Calvin Mooers (1951), que engloba "os aspectos intelectuais da descrição da informação e suas especificidades para a busca, além de quaisquer sistemas, técnicas ou máquinas empregadas para o desempenho da operação" (SARACEVIC, 1996, P.45).
} 
Várias linhas de pesquisa puderam ser incorporadas dentro das áreas de concentração, levando em conta as funções do ciclo informacional: de (i) aquisição e preservação, (ii) de organização de materiais e (iii) de difusão de informações. Na aquisição e preservação, adquirindo materiais com vista às necessidades do usuário; na organização de materiais, tornando seu acesso mais acessível aos usuários (por meio de diversas técnicas de recuperação da informação como as bibliografias, catalogação simplificada ${ }^{40}$, etc.); e na difusão de informações, propiciando o encontro dos leitores com os livros (serviço de referência, mediação da informação, desenvolvimento de competência informacional).

Interessante observar que o desenvolvimento da competência informacional foi desenvolvido inicialmente no âmbito empresarial, para solucionar problemas, tais como competência no uso de ampla variedade de recursos informacionais disponíveis na instituição ou empresa, para a solução de problemas (ZURKOWSKY, 1974) ${ }^{41}$. Usado nos Estados Unidos para designar habilidades ligadas ao uso da informação eletrônica, ela foi assimilada pela classe bibliotecária e atualmente insere-se de forma vigorosa no discurso dos bibliotecários (CAMPELO, 2003). É estudada em três níveis de complexidade: tecnologia da informação (dimensão instrumental, focado nos sistemas); cognição (biblioteca entendida como espaço de aprendizado, com foco no usuário); inteligência (dirigida para o aprendizado, com foco no processo) (DUDZIAK, 2003).

Com a evolução da área e interesse consolidado nas suas pesquisas, com cerca de 50 dissertações defendidas até a década de 1990, surgiu o interesse de criar um Doutorado em Ciência da Informação.

\section{Pós-Graduação em Ciência da Informação}

A partir de meados da década de 1960, as emergentes bases de dados automatizadas (machine readable data bases), representaram para a informação científica e tecnológica o seu maior desenvolvimento. Inicialmente concebidas para impressão automática de informações, tiveram sua utilização posterior dirigida para a recuperação da informação (GARCIA, 1980).

Impulsionada originalmente pelas ideias da Engenharia de Comunicação, teorias cibernéticas e sistemas de transmissão de sinais, que desenvolveram as bases para a caracterização dos modelos e processos de recuperação da informação (information retrieval) ${ }^{42}$, a Ciência da Informação (CI) também tomou como base elementos da Biblioteconomia Especializada e da Documentação. Enquanto a primeira estava muito atrelada aos aspectos sociológicos (herança da Escola de Chicago, 1930) e institucionais; a segunda foi praticamente substituída nos EUA pela Ciência da Informação, difundindo-se pela Europa. Lá, a

\footnotetext{
${ }^{40}$ Ver por exemplo: Cavalcanti, C. R. Catalogação simplificada. Brasília: UnB, 1970

${ }^{41}$ Dentro das empresas, a informação é organizada de acordo com as suas regras e dispositivos internos, podendo destinar-se à tomada de decisão, à resolução de problemas ou a serviços documentários, utilizada pelos membros da organização para cumprir seus objetivos e alguns dos seus usos são: monitoramento ambiental; sistemas de gestão de conhecimentos; sistemas de informação para gestão e/ou produção; ferramentas de groupware, workflow, Intranet. O indivíduo, no exercício de suas funções, encontra-se confrontado com diversos sistemas de informação, assistidos ou não por ferramentas tecnológicas, que são fruto de um projeto gerencial que eles descrevem e organizam (GUYOT, 2000).

${ }^{42}$ A recuperação da informação é um campo interdisciplinar amplo, que tem interfaces com a psicologia cognitiva, arquitetura informacional, design informacional, comportamento informacional, linguística, semiótica, ciência da informação, ciência computacional, biblioteconomia e estatística. Disponível em: <http://htwiki.slais.ubc.ca/index.php/Informationretrieval>. Acesso em: 01 de novembro de 2018.
} 
Documentação também incorporou as noções de automatização de serviços e técnicas, além de uma perspectiva de informação científica preocupada com o acesso e a recuperação, tendo surgido importantes centros de documentação e profissionalização.

O interesse nas bases de dados se deu no momento em que vários pesquisadores (americanos ${ }^{43}$, britânicos ${ }^{44}$ e russos ${ }^{45}$,) passaram a estudar a "comunicação da informação científica". Os processos por meio dos quais os cientistas buscavam os dados necessários para suas pesquisas, busca em bibliotecas, arquivos, museus, bases de dados, artigos de periódicos, e também junto a outros cientistas, isto é, a chamada comunicação informal (o colégio invisível). Estes estudos consolidaram a ideia de que na promoção do acesso e a disseminação da informação, a Ciência da Informação deveria ter por objeto, também, o estudo dos fluxos, dos caminhos percorridos pela informação, e sua materialização em diferentes produtos e serviços.

Na então URSS criou-se o termo Informatika, conceito construído pelos autores Chernyl, Gilyarevskii e Mikhailov (1966). O objeto dessa disciplina era estudar a estrutura e as peculiaridades da informação científica, bem como as leis que regiam tal atividade, sua história, teoria, método e formas de organização. Dessa forma, o ponto chave de estudo era a informação no contexto comunicativo de um sistema social voltado à mudança de estado do conhecimento, ideia que se aproximava de uma das vertentes do estudo da Ciência da Informação, que considerava o objeto de estudo - a informação - como potencial transformador do estado anômalo do conhecimento.

O conhecimento acumulado pela Ciência da Informação $(\mathrm{Cl})$ ao longo de sua evolução vem permitindo a compreensão da informação em todas essas dimensões (a física, a cognitiva e a social), ou seja, movendo-se dos registros físicos para sua dimensão significativa e sua inserção no campo da ação humana. São contemplados, nesta perspectiva, os diferentes suportes materiais, contextos institucionais e práticas humanas em torno dos registros materiais e da dimensão imaterial do conhecimento humano. Características da área incluem: preocupação com a circulação e disseminação do documento/informação; foco na informação contida no documento (conteúdo); atendimento aos usuários em sua frente de trabalho (ARAÚJO, 2014).

Tal proposta foi disseminada pela organização das Nações Unidas para a Educação Ciência e Cultura (Unesco), nos anos 1970, que em 1976 criou o Programa Geral da Informação (PGI) (GUICHAT; MENOU,1994). No Brasil, o Instituto Brasileiro de Informação em Ciência e Tecnologia (lbict) adotou essa visão em vários documentos e pesquisas ao longo da década e criou o primeiro Mestrado em Ciência da Informação em 1970, em parceria com a Universidade Federal do Rio de Janeiro (UFRJ).

\subsection{Doutorado em Ciência da Informação}

A Ciência da Informação como área do conhecimento engloba os aspectos relativos ao registro, processamento, armazenamento, difusão, recuperação e uso da informação documentária, independentemente do tipo de suporte em que foi registrado. Representa, provavelmente, o único conceito capaz de identificar os aspectos de multidisciplinaridade e

\footnotetext{
${ }^{43}$ BUTLER, L. P. An introduction to library science. Chicago: University of Chicago Press, 1933.

${ }^{44}$ FARRADANE, J. The scientific approach for Documentation. Royal Scientific Information Conference, 1948.

${ }^{45}$ MIKHAILOV, A. I.; CHERNIY, A.I.; GILIAREVSKI, R. S. Informatics, a new name for theory of scientific information. Nauchno - Tekhnichesakaya Informatsiya, n. 12, p. 35-39, 1966.
} 
interdisciplinaridade que caracterizam os processos de registro e transferência dos conhecimentos em toda a sua abrangência.

O argumento acima foi usado na proposta para a criação do Curso de Doutorado em Ciência da Informação, encaminhado em 1991.

É importante frisar que a Ciência da Informação apresenta superposição e complementaridade de significados entre informação e conhecimento, extrapolando os limites teóricos e técnicos da Biblioteconomia e da Documentação e também das disciplinas de Arquivologia e Museologia, quando focadas, principalmente, na preservação documentaria (função custodial). Avanços mais recentes nesses campos têm buscado agregar as várias contribuições das últimas décadas, que priorizam o estudo dos fluxos e a circulação da informação numa visão sistêmica do fluxo documental, bem como técnicas digitais (ARAúJO, 2014).

Segue a argumentação de que aos 25 anos da formatura da primeira turma de Biblioteconomia na UnB, a criação desse curso representa uma evolução natural e coerente das suas atividades. Representa o aprofundamento e expansão do ensino e pesquisa de áreas abrangidas pela Biblioteconomia e Documentação, privilegiando agora também o estudo do fluxo da informação para tornar mais eficiente a transferência do conhecimento, respondendo não só à evolução dessas áreas, mas também às exigências da sociedade, dando mais um passo no caminho da consolidação da investigação científica que caracteriza, no mundo inteiro, a expressão Ciência da Informação.

A proposta visou a consolidação do Programa de Pós Graduação, stricto sensu, pretendendo oferecer aos profissionais de diversas áreas a oportunidade de aprimorar suas competências científicas, e sua capacidade de realizar pesquisas originais na área de Ciência da Informação.

Para a Ciência da Informação, o conceito "informação" é utilizado na acepção de "conhecimento comunicado". Inclui conceitos de novidade e relevância, refere-se ao processo de transformação do conhecimento possibilitando a seleção e interpretação num contexto específico (CAPURRO; HJÖRLAND, 2007). Com esse entendimento, a área de concentração passa a ser a de "Transferência da Informação".

O desenvolvimento da pesquisa, desde a implantação de seu Mestrado em Biblioteconomia e Documentação, há doze anos, já tinha formado mais de 50 mestres, englobando não apenas a Biblioteconomia e Documentação, mas também aspectos relevantes da Ciência da Informação, da Gestão da Informação, e da Gestão do Conhecimento ${ }^{46}$, fortemente apoiadas nas tecnologias da informação, com foco em recuperação da informação, estudos de usuários, estudos de necessidades informacionais e usos da informação, competência informacional, serviço de informação, sistemas de informação, entre outros.

Com a implantação do Doutorado em Ciência da Informação, efetivamente criado em 1992, o Mestrado em Biblioteconomia e Documentação passa a denominar-se Mestrado em Ciência da Informação, em 1995.

Anteriormente, em 1991, foi criado o Curso de Arquivologia ${ }^{47}$, comportando entendimento complementar do objeto de estudo da documentação e da informação. Este

\footnotetext{
${ }^{46}$ São áreas de interesse da Ciência da Informação, a Gestão da Informação, a Inteligência Competitiva e a Gestão do Conhecimento (HAWKINS, 2001, p.51).

${ }^{47} \mathrm{O}$ seu reconhecimento pelo então Conselho Federal de Educação ocorreu em 1995.
} 
curso visa abarcar a gestão de arquivos públicos e privados existentes no Distrito Federal, e a preservação da memória nacional, orientando-se para arquivos administrativos, atendendo à demanda de organização da documentação produzida e acumulada pela administração federal.

Em 2009 é criado o Curso de Museologia ${ }^{48}$, indo ao encontro da orientação da Unesco, de reunir cursos com o mesmo objeto de estudo - a informação. Sua criação teve a participação direta de quatro unidades acadêmicas da UnB: Antropologia, Artes, Ciência da Informação e História. Desta forma a interdisciplinaridade da área foi garantida, abrindo espaço para interações optativas com outras áreas do conhecimento. Seus quatro eixos temáticos são: Teoria e Prática Museológica; Museologia e Informação; Museologia e Patrimônio Cultural; e Preservação e Conservação de Bens Culturais. A fim de ampliar a aproximação entre os cursos, foi criada a Comissão de Integração Curricular cujos resultados estão no documento Identificação do Eixo Integrador: tronco comum de disciplinas da $\mathrm{FCl}^{49}$ (ALVARES, 2012).

Consolidou-se assim a proposta de ensino nas áreas mais significativas para o desenvolvimento da Ciência da Informação, convertendo-se no dia 3 de maio de 2010 pelo Conselho Universitário (CONSUNI) o Departamento de Ciência da Informação e Documentação (CID) em Faculdade de Ciência da Informação (FCI). Esta ficou integrada, portanto, pelos cursos de Biblioteconomia (1965), Arquivologia (1991) e Museologia (2008), além da PósGraduação em Ciência da Informação, englobando o já criado Mestrado (1978) e o Doutorado em Ciência da Informação (1992).

\subsubsection{Corpo docente}

Atualmente a pós-graduação conta com dezoito (18) professores permanentes e oito (8) professores colaboradores.

Desde a sua gênese até os dias de hoje, a maioria dos docentes esteve e está fortemente comprometida com a pós-graduação, tanto no mestrado quanto no doutorado. Todos orientam em média de 2 a $8^{50}$ trabalhos, de acordo com a recomendação da Capes. Também colaboram majoritariamente com as iniciativas de Doutorado Interinstitucional (Dinter), como, por exemplo, no último Dinter com a Universidade Federal do Espírito Santo (UFES), concluído em 2015, que formou 11 doutores, oriundos dos cursos de Arquivologia, Biblioteconomia e Ciências Contábeis daquela Universidade.

48

em: <http://repositorio.unb.br/bitstream/10482/12133/1/ARTIGO_GraduacaoMuseologiaSignifcados.pdf> Acesso em 04.11.2018.

${ }^{49} \mathrm{O}$ eixo temático - museologia e informação - congrega disciplinas compartilhadas pelos cursos de Biblioteconomia e Arquivologia, junto às quais se perfila uma nova disciplina centrada no processamento técnico de acervos realizado no campo da Museologia. Constituem um embrião do tronco comum aos três cursos da Faculdade de Ciência da Informação - Biblioteconomia, Arquivologia e Museologia - com perspectivas de amadurecimento e transformação objetivando configurar-se numa área de conhecimento comum. Disponível em <http://www.museologia.fci.unb.br/curso/curriculo >. Acesso em: 05.11.2018

\footnotetext{
${ }^{50}$ Desde 2014, entretanto, optou-se por reduzir o número de orientandos por professor para 6 alunos regulares mais 1 aluno de Dinter, com vistas a garantia de qualidade no acompanhamento dos discentes.
} 
Atividades administrativas têm sido assumidas também pelos professores e a Tabela 1 traz a relação dos coordenadores do Programa de Pós-Graduação.

Tabela 1 - Histórico de Coordenadores do PPGCINF

\begin{tabular}{|c|c|c|}
\hline $1978-1980$ & Nice de Menezes Figueiredo & Mestrado em Biblioteconomia e Documentação \\
\hline $1980-1981$ & Jaime Robredo & Mestrado em Biblioteconomia e Documentação \\
\hline $1981-1985$ & KiraTarapanoff & Mestrado em Biblioteconomia e Documentação \\
\hline $1985-1987$ & Jaime Robredo & Mestrado em Biblioteconomia e Documentação \\
\hline $1987-1988$ & KiraTarapanoff & Mestrado em Biblioteconomia e Documentação \\
\hline $1988-1990$ & Jaime Robredo & Mestrado em Biblioteconomia e Documentação \\
\hline $1991-1992$ & Tânia Mara Botelho & Mestrado em Biblioteconomia e Documentação \\
\hline $1992-1993$ & Marcílio de Brito & $\begin{array}{l}\text { Mestrado em Biblioteconomia } \\
\text { Doutorado em Ciência da Informação }\end{array}$ \\
\hline $1993-1995$ & Suzana Pinheiro Machado Mueller & $\begin{array}{l}\text { Mestrado em Biblioteconomia } \\
\text { Doutorado em Ciência da Informação }\end{array}$ \\
\hline $1995-1997$ & Suzana Pinheiro Machado Mueller & Mestrado e Doutorado em Ciência da Informação \\
\hline $1997-2000$ & Emir José Suaiden & Mestrado e Doutorado em Ciência da Informação \\
\hline $2000-2004$ & Sueli Angélica do Amaral & Mestrado e Doutorado em Ciência da Informação \\
\hline $2004-2006$ & Sely Maria de Souza Costa & Mestrado e Doutorado em Ciência da Informação \\
\hline $2006-2008$ & Antônio Lisboa Carvalho de Miranda & Mestrado e Doutorado em Ciência da Informação \\
\hline $2008-2010$ & Sofia Galvão Baptista & Mestrado e Doutorado em Ciência da Informação \\
\hline $2010-2012$ & André Porto Ancona Lopez & Mestrado e Doutorado em Ciência da Informação \\
\hline $2012-2014$ & Lillian Alvares & Mestrado e Doutorado em Ciência da Informação \\
\hline $2014-2015$ & Georgete Medleg Rodrigues & Mestrado e Doutorado em Ciência da Informação \\
\hline $2015-2016$ & Fernando César Lima Leite & Mestrado e Doutorado em Ciência da Informação \\
\hline
\end{tabular}




\begin{tabular}{|l|l|l|}
\hline $2016-2018$ & Renato Tarciso Barbosa de Sousa & Mestrado e Doutorado em Ciência da Informação \\
\hline $2018-$ & João de Melo Maricato & Mestrado e Doutorado em Ciência da Informação \\
\hline
\end{tabular}

\subsection{Linhas de pesquisa}

Criada em 2010, a Faculdade de Ciência da Informação (FCl), em seu programa de pósgraduação (PPGCINF), engloba áreas de interesse da Biblioteconomia, Ciência da Informação, Arquivologia e Museologia. Constrói sua base conceitual a partir dos processos do ciclo vital da informação que tem como vigas mestras a gênese da informação, a organização da informação, a recuperação da informação e a comunicação da informação, conforme Figura 1.

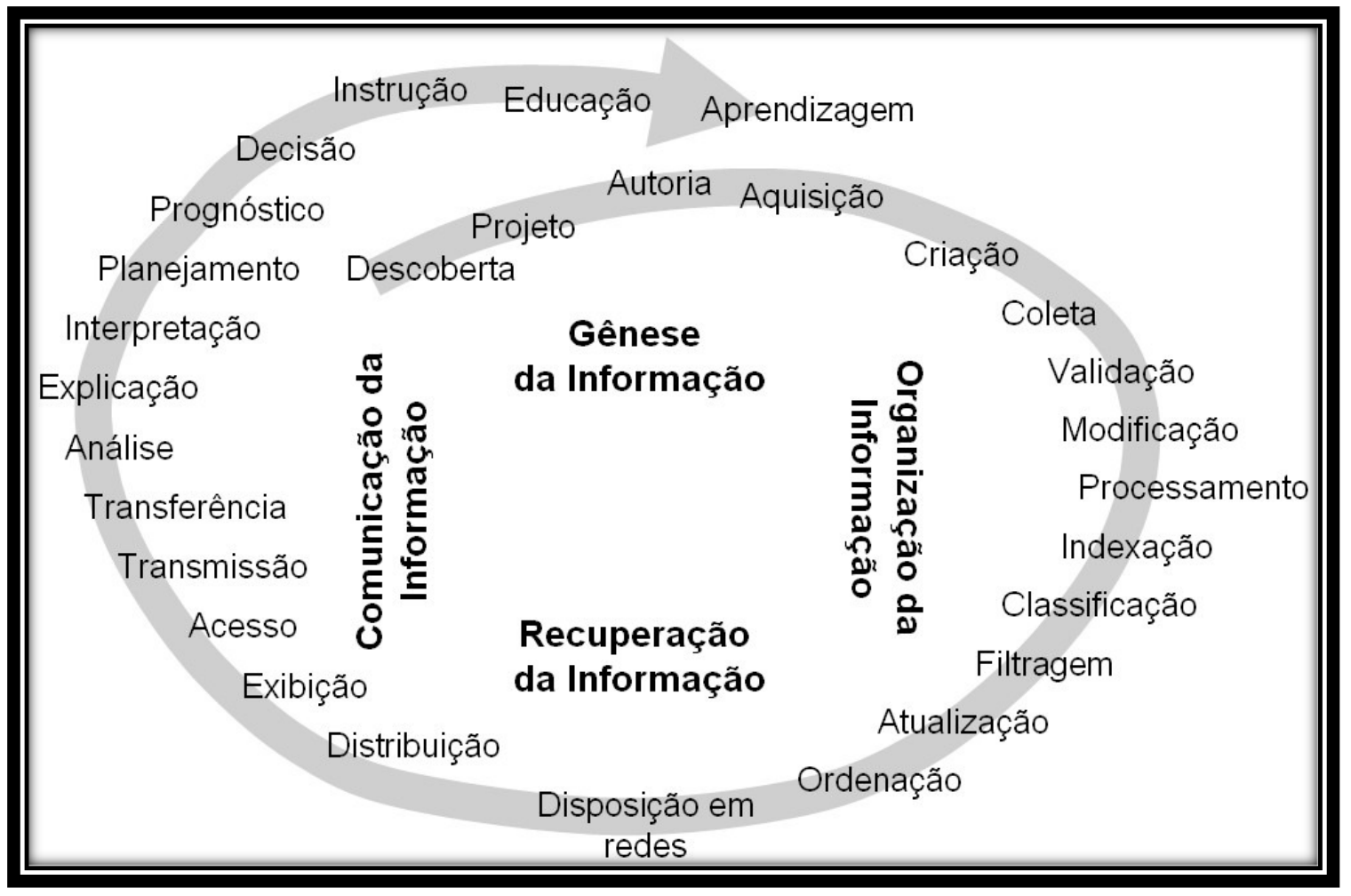

Figura 1 - Síntese da concepção do ciclo informacional

Fonte: (UnB/FCl, 2010, p. 2).

Atualmente suas linhas de pesquisa são (i) Organização da informação e (ii) Comunicação e Mediação da Informação. No que se refere à primeira (Organização da Informação), ela pretende criar conhecimento nos níveis epistemológico, científico e prático relativos ao ciclo informacional. Relaciona-se com a natureza da informação; os modelos de tratamento e recuperação de informações e terminologias; as necessidades dos usuários da informação; a formulação de políticas, estratégias, planejamento, normas e processos relacionados a diferentes espaços de informação. No que se refere à Comunicação e Mediação da Informação, ela relaciona-se com o desenvolvimento de conhecimentos nos níveis epistemológico, científico e prático sobre processos de comunicação em diversos contextos e 
setores da sociedade e o entendimento de fenômenos relativos ao fluxo da informação, aos atores participantes e aos canais utilizados.

\section{Análise do PPGCINF de 2006 a 2018}

Das mais de 400 dissertações e teses defendidas desde o Mestrado em Biblioteconomia e Documentação uma breve análise do PPGCINF pode ser realizada no período de 2006 a 2018, em razão de apenas a partir de 2006 as instituições com programas de pós-graduação stricto sensu terem sido obrigadas a depositar os seus resultados de pesquisa nos repositórios institucionais. Assim, a análise contempla 389 pesquisas do total de 440 disponíveis no repositório de teses e dissertações da Universidade de Brasília ${ }^{51}$. Os 51 demais registros se encontram no repositório de 1979-2005.

Ressalte-se que o repositório da UnB, que inclui também a produção de teses e dissertações da $\mathrm{FCl}$, fonte dos dados desta pesquisa, integra uma importante iniciativa do Instituto Brasileiro de Informação em Ciência e Tecnologia (IBICT), a Biblioteca Digital Brasileira de Teses e Dissertações (BDTD) ${ }^{52}$, banco de dados que contém os resultados da pós-graduação stricto sensu do Brasil, com 607.718 documentos (168.000 Teses e 439.718 Dissertações) ${ }^{53}$, oriundos de 105 instituições brasileiras, baseados no Open Archives Initiative Protocol for Metadata Harvesting (OAI-PMH), protocolo desenvolvido pela Open Archives Initiative que define um mecanismo para coleta de registros de metadados em repositórios de dados, adotando assim, o modelo baseado em padrões de interoperabilidade.

\subsection{Metodologia}

A metodologia aqui utilizada foi a mineração de dados a partir de dados estruturados, por meio de softwares de preparação (incluindo limpeza), extração, tratamento, processamento (incluindo visualização), interpretação e análise de dados, processo conhecido como Descoberta de Conhecimento em Bases de Dados ou em inglês Knowledge Discovery in Databases (KDD). A seleção das ferramentas foi feita a partir do referencial de software livre, sendo o Knime para estatísticas e mineração de dados, Open Refine para carregamento e leitura dos dados e Tableau para limpeza, transformação e visualização dos dados. A propósito, o processo de análise de informação exige que a fonte de dados esteja homogênea e sem ruídos informacionais. Foi nesse aspecto que se verificou a maior barreira a ser superada: o processo de limpeza e padronização dos dados, que consumiu parte significativa do tempo de pesquisa.

Como já informado, o período de avaliação foi de 2006 a 2018, tendo em vista a confiabilidade dos dados, pois somente a partir de 2006 as instituições que oferecem programas de pós-graduação stricto sensu foram obrigadas a depositar os seus resultados de

51Conforme o Repositório de Teses e Dissertações da FCI na base da Biblioteca Central da UnB - http://repositorio.unb.br/handle/10482/5363

${ }^{52} \mathrm{~A}$ BDTD é uma rede distribuída de repositórios institucionais de teses e dissertações, com texto completo. As instituições com oferta de mestrado e doutorado são as provedoras de informações e o IBICT as agrega. Isso é, o processo abrange a coleta dos metadados das teses e dissertações dos provedores (instituições de ensino e pesquisa), organiza-os em um único repositório e os expõem para coleta para outros provedores de serviços, como por exemplo, o Portal Brasileiro de Publicações Científicas em Acesso Aberto (OASISBR) e a Networked Digital Library of Theses and Dissertations (NDLTD), organização internacional que promove a criação, divulgação e preservação de teses e dissertações eletrônicas de vários países (http://www.ndltd.org/).

53Dados de 3 de novembro de 2018 
pesquisa nos repositórios institucionais. Esse fato não se limitou a que os registros no repositório sejam apenas desse período de tempo; ao contrário, as instituições alimentam retrospectivamente seus repositórios institucionais e o da UnB possui registros da Ciência da Informação desde 1979. Para a presente pesquisa, no entanto, o período considerado garantiu a completeza do conjunto de dados adotado. Depois, notou-se a necessidade de restringir ainda mais o período em algumas análises para 2017, uma vez que a extração do conjunto de dados de interesse foi realizada em 2018 e, portanto, uma parcela das informações ainda não está presente na base.

No que se refere à análise dos dados e descoberta de informação, optou-se pela mineração de dados com fins de descrição e predição, com abordagens de classificação (mapeamento de dados para agrupamento em classes principais), regressão (descoberta de relações entre as variáveis), clustering (identificação de um conjunto de dados com as características semelhantes) e sumarização (descrição do conhecimento).

\subsection{Evolução por ano de mestrados e doutorados}

\subsubsection{Trabalhos desenvolvidos}

O gráfico 1 mostra o número total de defesas no período de 2006 a 2018 (este último ano ainda incompleto no repositório da UnB). Ao todo, foram defendidas 148 teses de doutorado e 241 dissertações de mestrado, somando um total de 389 pesquisas em Ciência da Informação.

Gráfico 1 - Número de pesquisas defendidas de 2006 a 2018

\section{Pesquisas Finalizadas em Mestrado e Doutorado}

Tipo
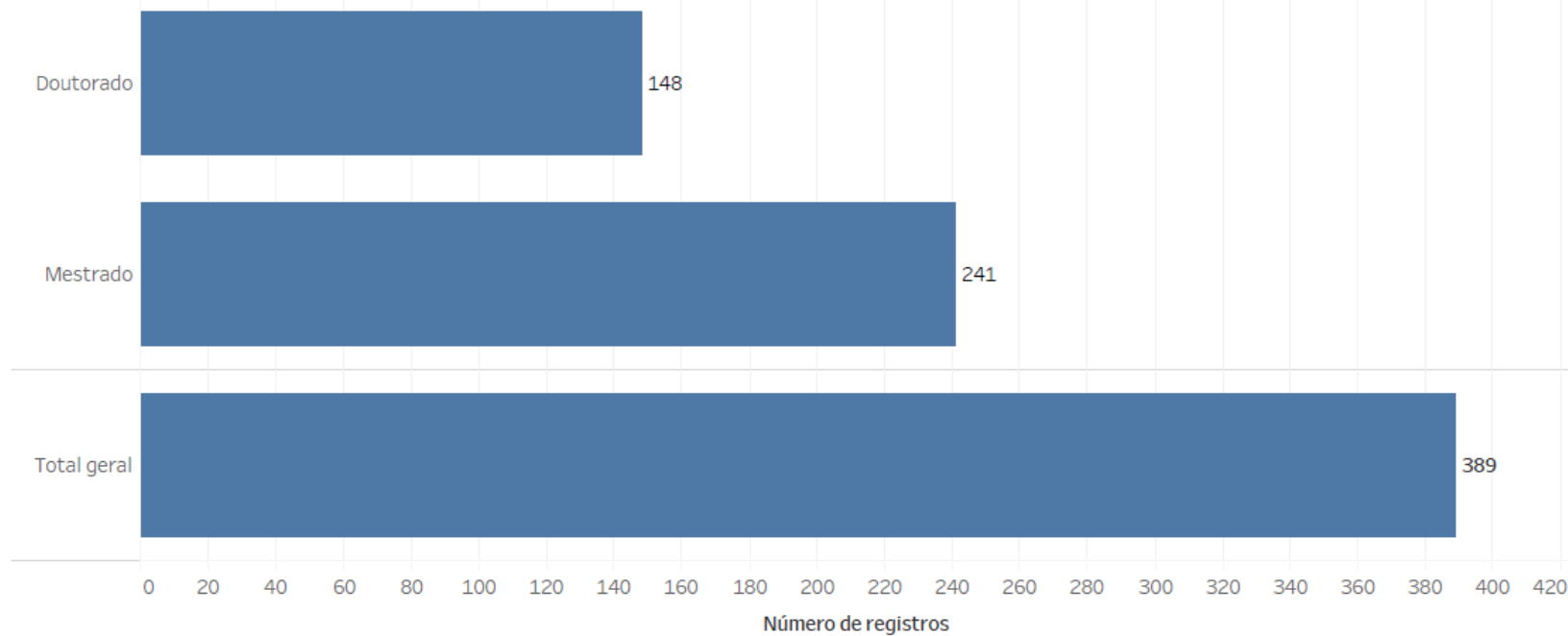

O significado deste número pode ser melhor entendido se comparado aos resultados de pesquisa no repositório institucional da UnB para o período de 2006 a 2016, que congrega resultados de todos os mestrados e doutorados da instituição. Neste período o PPGCINF somou 343 defesas no total (uma diferença para 2018 de 46 novos documentos). Naquele 
levantamento, o PPGCINF ocupava a oitava posição, entre 109 programas, ficando, portanto, entre os oito programas mais produtivos de pós-graduação da Universidade de Brasília ${ }^{54}$ (ALVARES, 2017), conforme mostra o gráfico 2.

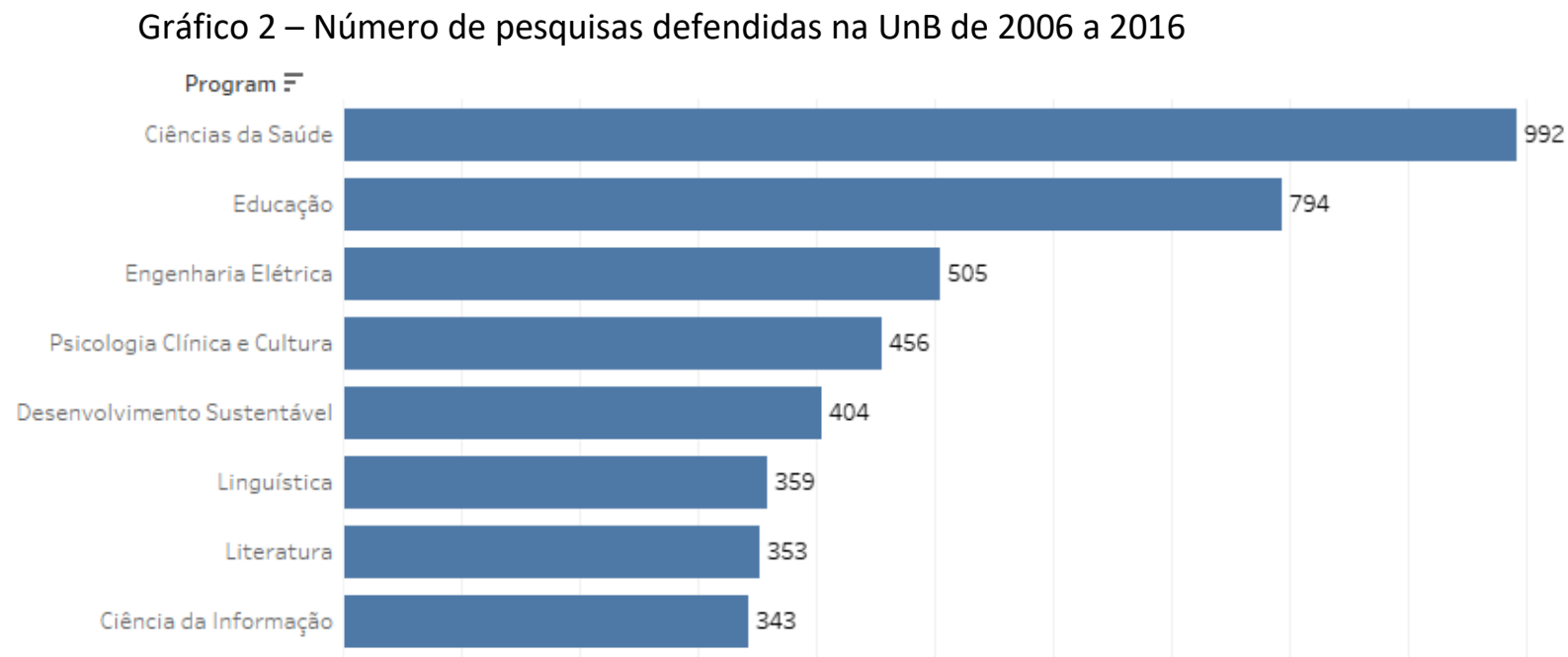

\subsubsection{Evolução das defesas}

Observa-se que o número de defesas de mestrado e doutorado do PPGCINF não é regular, apresenta variações significativas de um ano para o outro. Entre 2006 a 2017 (período analisado), o extremo registrado está no ano de 2015 (com 45 defesas), 6 a mais do que em 2013 (39 defesas, o maior registro até então (gráficos 3 e 4).

${ }^{54}$ Os demais 101 programas são: administração, administração (profissional), agronegócios, agronomia, antropologia (Proex), arquitetura e urbanismo, artes, artes cênicas, bioética, biologia animal, biologia microbiana, biotecnologia e biodiversidade, botânica, ciência política, ciências ambientais, ciências animais, ciências biológicas (biologia molecular) (Proex), ciências contábeis, ciências da reabilitação, ciências da saúde, ciências de materiais, ciências do comportamento, ciências e tecnologias em saúde, ciências farmacêuticas, ciências florestais, ciências mecânicas, ciências médicas, computação aplicada, comunicação, contabilidade, desenvolvimento sustentável, desenvolvimento sustentável (profissional), desenvolvimento, sociedade e cooperação internacional, design, direito, direitos humanos e cidadania, ecologia, economia, economia (profissional), educação, educação (profissional), educação em ciências, educação física, educação física (profissional), enfermagem, engenharia biomédica, engenharia de sistemas eletrônicos e de automação, engenharia elétrica, engenharia elétrica (profissional), ensino de ciências, ensino de física (profissional), ensino de ciências, ensino de física (profissional), estatística, estruturas e construção civil, estudos comparados sobre as américas, estudos de tradução, filosofia, física, fitopatologia, geociências aplicadas e geodinâmica, geografia, geologia (Proex), geotecnia (Proex), gestão pública (profissional), história, informática, integridade de materiais da engenharia, linguística, linguística aplicada, literatura, matemática (Proex), matemática em rede nacional - profissional, medicina tropical, meio ambiente e desenvolvimento rural, metafísica, música, nanociência e nanobiotecnologia, nutrição humana, odontologia, patologia molecular, política social, processos de desenvolvimento humano e saúde, profartes (rede), profbio (rede), propriedade intelectual e transferência de tecnologia, psicologia clínica e cultura, psicologia social, do trabalho e das organizações, química, regulação e gestão de negócios (profissional), relações internacionais, saúde animal, saúde coletiva, saúde coletiva (profissional), sistemas mecatrônicos, sociologia, tecnologia ambiental e recursos hídricos, tecnologias química e biológica, transportes, turismo (profissional), zoologia 
Uma possível análise do fato é o vínculo com a avaliação trienal dos programas de pósgraduação da Capes que no final de 2014 rebaixou o Programa da já tradicional nota 5 do PPGCINF para 4. O fato mudou a rotina dos professores, que buscaram retomar o histórico patamar de excelência. Nos quatro anos seguintes (2014, 2015, 2016 e 2017), já com a mudança para avaliação quadrienal da Capes, o corpo docente dedicou-se intensamente a concluir pesquisas em andamento e iniciar novas pesquisas a fim de produzir as respectivas comunicações científicas em número e em qualidade. Certamente, o corpo discente sentiu a pressão já no primeiro ano e acabou por concluir um grande número de orientações no ano de 2015.

Outro fato que chama atenção é a curva de tendência em declínio para o mestrado. De fato, a tendência já era observada pelos membros do PPGCINF, pois apesar de em termos absolutos haver mais alunos de mestrado e mais dissertações defendidas por ano, como mostra o gráfico 3, o crescimento do número de defesas de teses é progressivo e permanente no ritmo observado no gráfico do doutorado, o que, no entanto, não se observa no gráfico do mestrado. Este último aspecto merece um estudo aprofundado de suas causas.

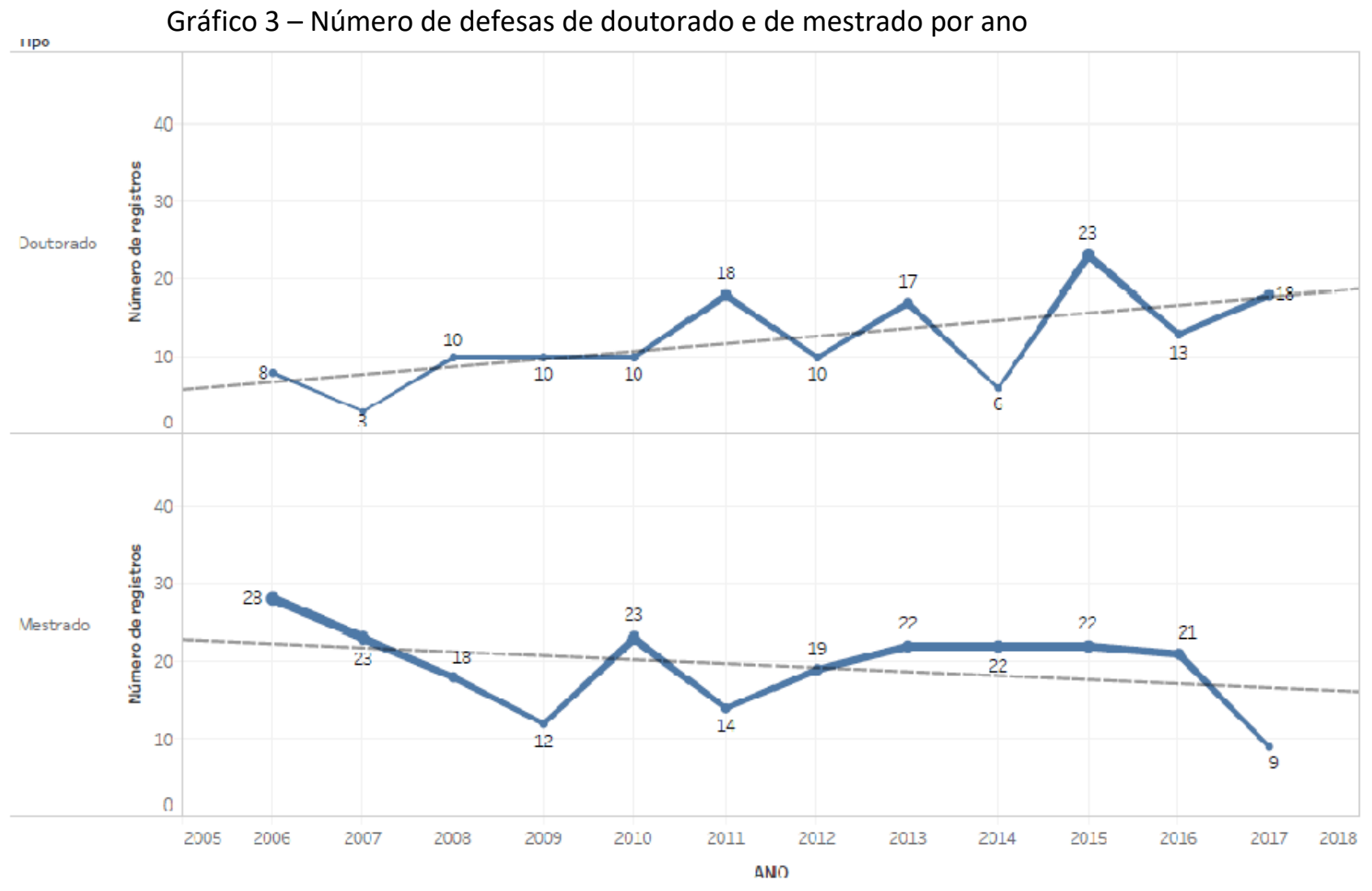

Gráfico 4 - Soma das defesas de doutorado e de mestrado por ano 


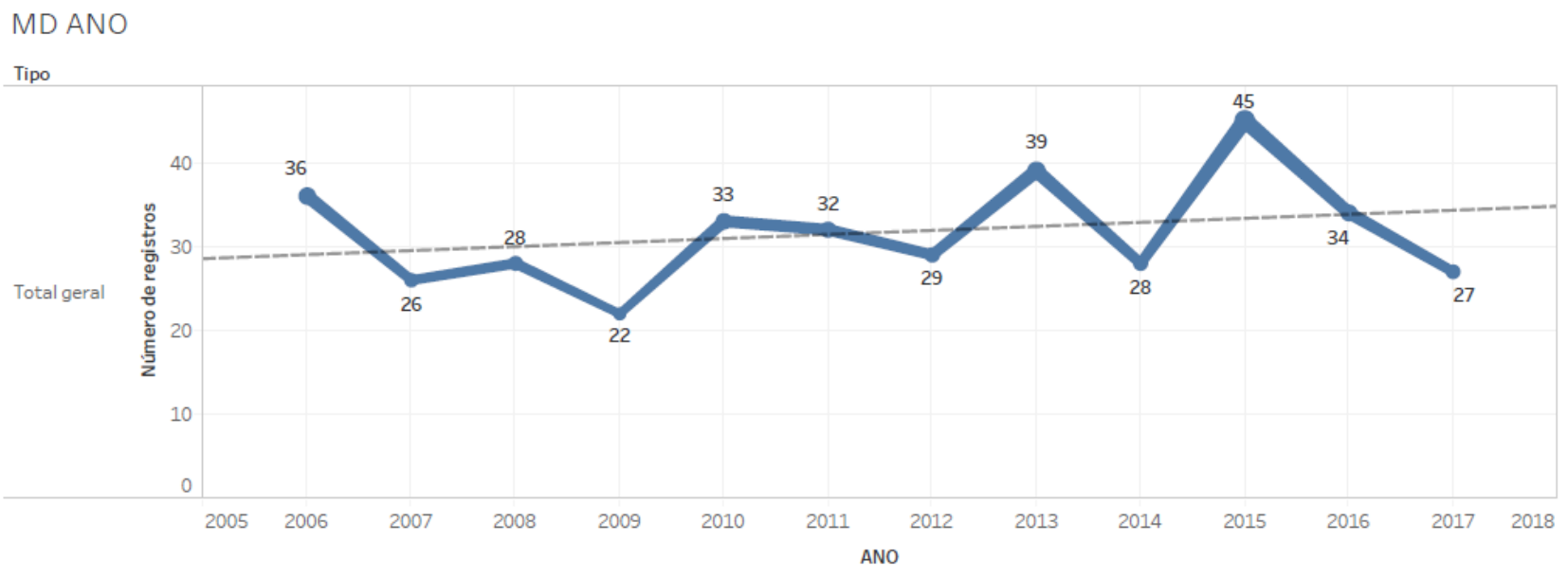

\subsection{Principais palavras-chave}

A norma técnica da ABNT NBR 6028:2003 define palavra-chave (PC) como a expressão representativa do assunto ou conteúdo da pesquisa, escolhida, preferencialmente, a partir de um vocabulário controlado. Os descritores, por sua vez, são expressões selecionadas em um vocabulário controlado, para uniformizar os sinônimos de modo a facilitar e garantir a qualidade da recuperação da informação. No repositório institucional da UnB os termos e expressões que caracterizam a pesquisa são selecionados aleatoriamente pelos autores das pesquisas, isto é, sem consulta prévia de um vocabulário controlado e sem uma lógica de apresentação dos termos. A seleção das palavras-chave, por conseguinte, traz consigo uma imprecisão: cada autor caracteriza seu trabalho de acordo com sua própria lógica e organização semântica. Para alguns, a primeira palavra-chave é o termo mais específico da pesquisa, seguindo as demais palavras-chave para o termo mais genérico. Outros autores, por sua vez, utilizam a lógica contrária, sendo a primeira palavra-chave a mais genérica, seguindo para a última palavra-chave mais específica.

Essa situação gerou a necessidade de considerar uma ampla lista com todas as palavras-chave utilizadas, independente da posição que ocupavam. Foram observadas, portanto, 699 palavras-chave, de 1569 citadas. O Gráfico 5 apresenta apenas uma lista reduzida, com as primeiras vinte ocorrências.

\section{Gráfico 5 - Palavras-chave}




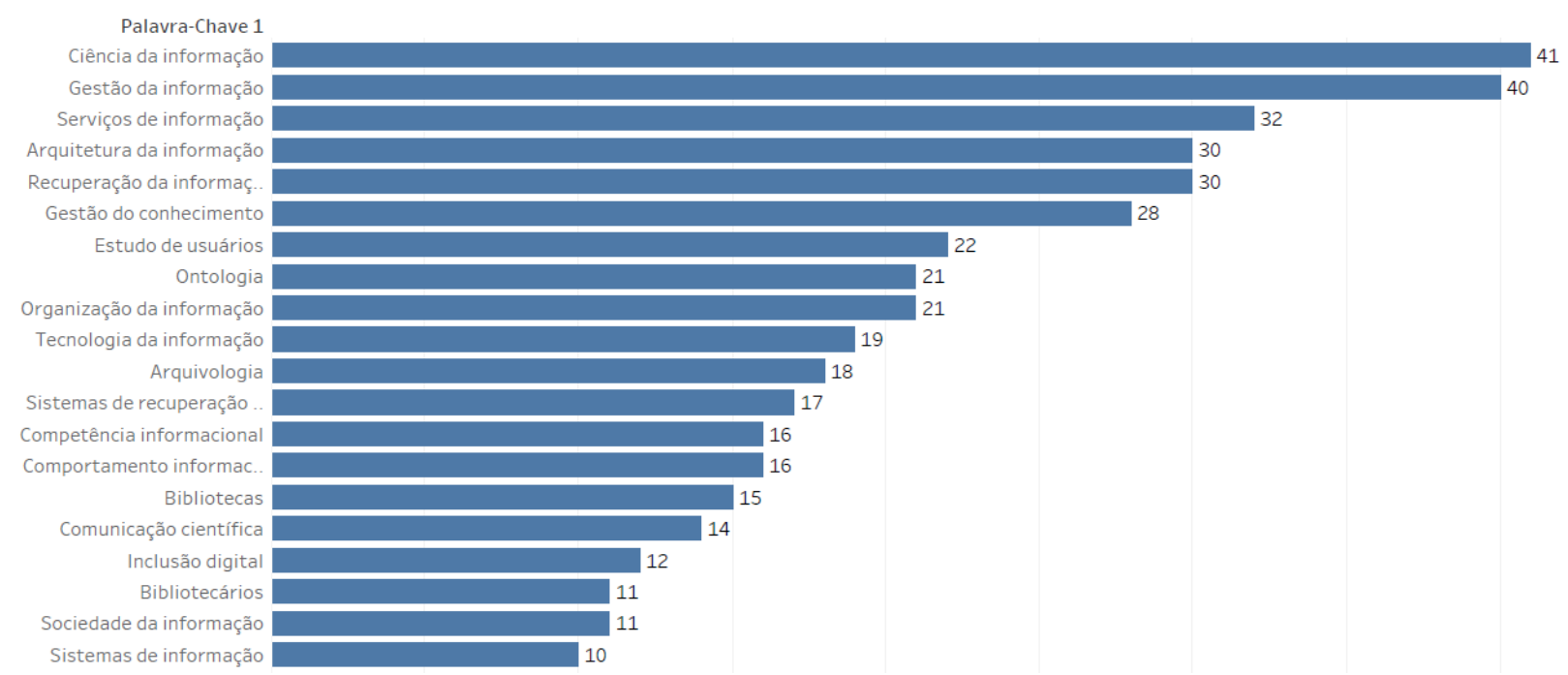

A primeira palavra-chave mais citada é Ciência da Informação. Existem algumas interpretações possíveis. A primeira, naturalmente, é que o PPGCINF é o lócus exato para estudos históricos e epistemológicos da Ciência da Informação. E de fato, parte das 41 pesquisas que citam esta palavra-chave deve estar nesse contexto. Mas a segunda possibilidade, mais prosaica, é que os autores podem se sentir impelidos a citar que a pesquisa está contida no domínio da Ciência da Informação. Mas nesse caso é impossível determinar qual o objeto da pesquisa apenas com a análise do grande grupo das palavras-chave. As palavras seguintes representam melhor os temas atuais e prioritários da $\mathrm{Cl}$, cujas possibilidades de investigação são abordadas no PPGCINF. De um modo geral, observa-se a não uniformidade de uso de palavras chaves. Conclui-se pela necessidade de orientar mestrandos e doutorandos quanto à escolha de palavras de fato significativas quanto ao conteúdo representado em suas pesquisas.

\subsubsection{Primeira palavra-chave}

As possíveis análises sobre temáticas mais detalhadas de pesquisa no PPGCINF a partir de palavras-chave decorrem da associação entre as palavras-chave selecionadas pelos próprios autores das pesquisas. Para isso, é preciso considerar as palavras-chave como informadas a fim de compreender melhor os temas tratados. Os gráficos 6 e 7 trazem essas informações, agora não mais considerando uma relação absoluta, mas sim como os metadados informados. Considerando a primeira palavra-chave, Ciência da Informação passou de 41 citações para 11, sendo agora a terceira palavra-chave mais citada. A primeira palavra-chave mais citada, por sua vez, é Arquitetura da Informação, denotando algumas possibilidades. A primeira, muitos professores orientam nesse tema e, portanto, ele se destaca no perfil do PPGCINF. Segundo, o tema é prioritário na sociedade e tem trazido alunos para investigação em torno dele. Terceiro, é um termo genérico, utilizado pelos especialistas para denotar todos os aspectos da tecnologia da informação e suas interfaces. 0 gráfico 6 , apresenta também um extrato das ocorrências, representando apenas as mais citadas.

\section{Gráfico 6 - Primeira Palavra-chave}




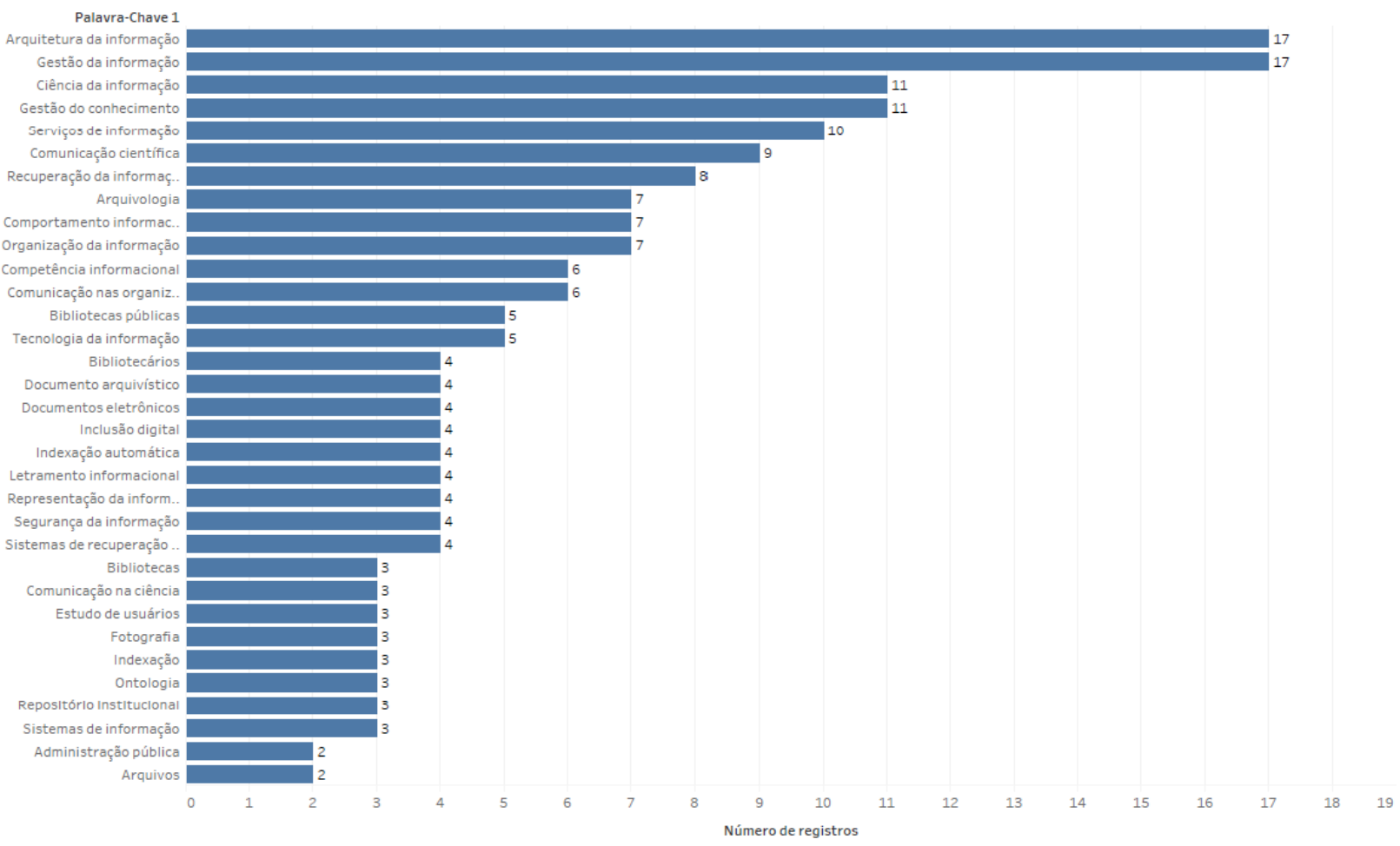

As demais palavras-chave mantêm o já previsto no gráfico 5, sendo Gestão da Informação (segundo lugar em ocorrência) uma das mais citadas tanto em termos absolutos quanto em termos relativos. Cabe notar que a abrangência desse descritor traz a reboque várias possibilidades de pesquisa e por isso a combinação das várias palavras-chave informadas é essencial.

O gráfico 7 traz o exemplo de combinação da palavra-chave Arquivologia com as demais que descrevem as respectivas pesquisas. Da análise, pode-se concluir que o tema Arquivologia está associado à formação profissional, à gestão do documento arquivístico e às práticas arquivísticas. Com essas informações, pode-se traçar o perfil da pesquisa em Arquivologia no PPGCINF e quem são os professores que orientam nesse segmento.

Gráfico 7 - Combinação da primeira palavra-chave Arquivologia e as demais

\begin{tabular}{|c|c|c|c|c|c|}
\hline \multirow{8}{*}{ Arquivologia } & 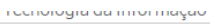 & vuluivyus & 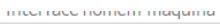 & ivaru & 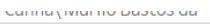 \\
\hline & formação & Arquivologia & história & Arquivologia & Sousa \Renato Tarciso Ba. \\
\hline & Arquivistas & Formação profissional & Mercado de trabalho & Nulo & Rodrigues $\backslash$ Georgete Med \\
\hline & Arquivologia & Estudo e ensino & Nulo & Nulo & Sousa \Renato Tarciso Ba. \\
\hline & Documento arquivístico & Nulo & Nulo & Nulo & Sousa\Renato Tarciso Ba. \\
\hline & Documentos públicos & Arquivos & Brasília (DF) & Serviços de informação & Sousa\ Renato Tarciso Ba. \\
\hline & Práticas arquivisticas & Disciplina científica & Nulo & Nulo & Rodrigues\Georgete Med \\
\hline & Processo administrativo & Gestão de documentos & Protocolo & Arquivologia & Sousa \Renato Tarciso Ba. \\
\hline
\end{tabular}

\subsubsection{Distribuição ao longo do ano}

Outra análise possível a partir da metodologia de estudos quantitativos por meio de análises estatísticas com tecnologias de mineração de dados é ver a evolução de determinada área no âmbito do PPGCINF (representada pelas palavras-chave). Por exemplo, o gráfico 8 mostra a dinâmica da área de Gestão do Conhecimento. Pode-se constatar que os anos de 
2008 a 2013 foram os mais produtivos nesta temática, coincidindo com um importante momento da disseminação do tema no Brasil e com o correspondente interesse dos docentes em atender a demanda. Mostra também que comunicação científica teve uma concentração de defesas em 2009 (4), com uma ocorrência espaçada em 2011 e só recentemente (a partir de 2016) com defesas regulares no Programa.

Gráfico 8 - Evolução das áreas palavras-chave no PPGCINF

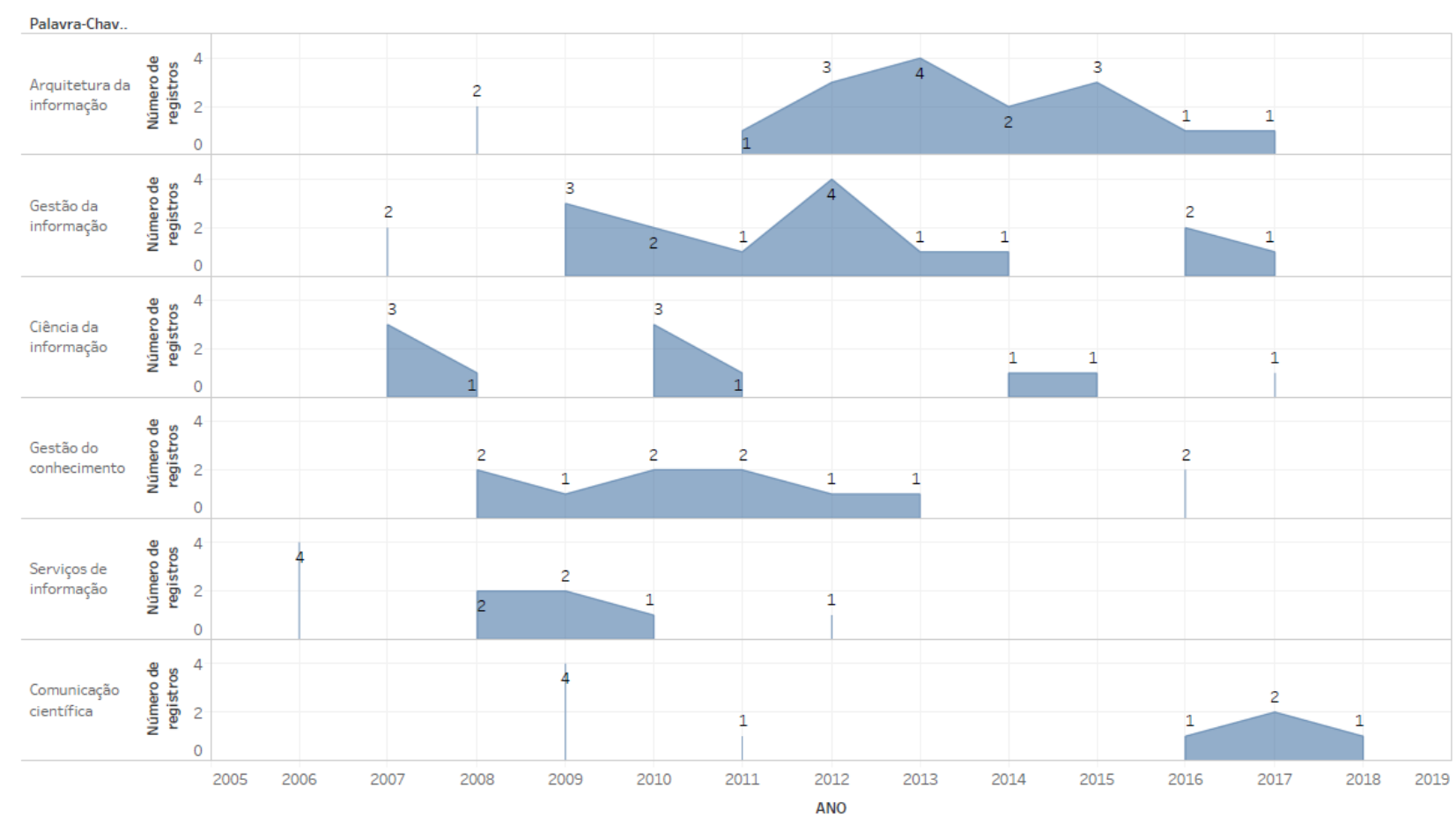

\subsection{Palavras-chave e grupos de pesquisa}

As temáticas de pesquisas diversificaram-se conforme a evolução da própria área da Ciência da Informação; da capacitação docente e dos interesses específicos de alunos e professores. O PPGCINF tem 19 Grupos de Pesquisa, sendo os da linha Organização da Informação, por antiguidade, os relacionados a seguir:

- Inteligência Organizacional e Competitiva, líder: Kira Tarapanoff (2000)

- Biblioteca Digital, líder: Murilo Bastos da Cunha (2000)

- Arquitetura da Informação, líder: Mamede Lima-Marques (2006)

- Imagem, Memória e Informação, líder: Miriam Paula Manini (2007)

- Acervos Fotográficos, líder: André Porto Ancona Lopez (2008)

- Representação e Organização da Informação e do Conhecimento, líder: Dulce Maria Baptista (2012)

- Museologia, Patrimônio e Memória, líder: Ana Lúcia de Abreu Gomes (2012) 
- Fundamentos históricos, epistemológicos e teóricos da Arquivologia, líder: Cynthia Roncaglio (2013)

- Arquitetura da Informação, Linguística Computacional e Multimodalidade, Mídias e Interatividade, líder: Cláudio Duque (2013)

- Estado, Informação e Sociedade, líder: Georgete Medleg Rodrigues (2014)

E os da linha Comunicação e Mediação da Informação, por antiguidade:

- Comunicação cientifica, líder: Jayme Leiro Vilan Filho (1994)

- Marketing da Informação, líder: Sueli Angelica do Amaral (1998)

- Publicações Eletrônicas, líder: Fernando César Lima Leite (2004)

- Biblioteca e Sociedade, líder: Emir José Suaiden (2006)

- Segurança da Informação e defesa Cibernética, líder: Jorge Henrique Cabral Fernandes (2007)

- Fatores Humanos na Interação e Comunicação da Informação, líder: Ivette Kafure Muñoz (2009)

- Competência em Informação, líder: Elmira Luzia Melo Soares Simeão (2011)

- Aprendizagem, Comportamento e Letramento informacional, líder: Kelley Cristine Goncalves Dias Gasque (2013).

Pela associação com a palavra-chave, é possível saber especificamente qual a abrangência efetiva dos grupos de pesquisa. O gráfico 9 traz essas informações. Por exemplo, pode-se saber quem são os professores que orientam em Gestão da Informação, palavrachave que pode estar associada a muitos dos grupos de pesquisa acima.

Gráfico 9 - Orientadores e suas linhas de pesquisa 


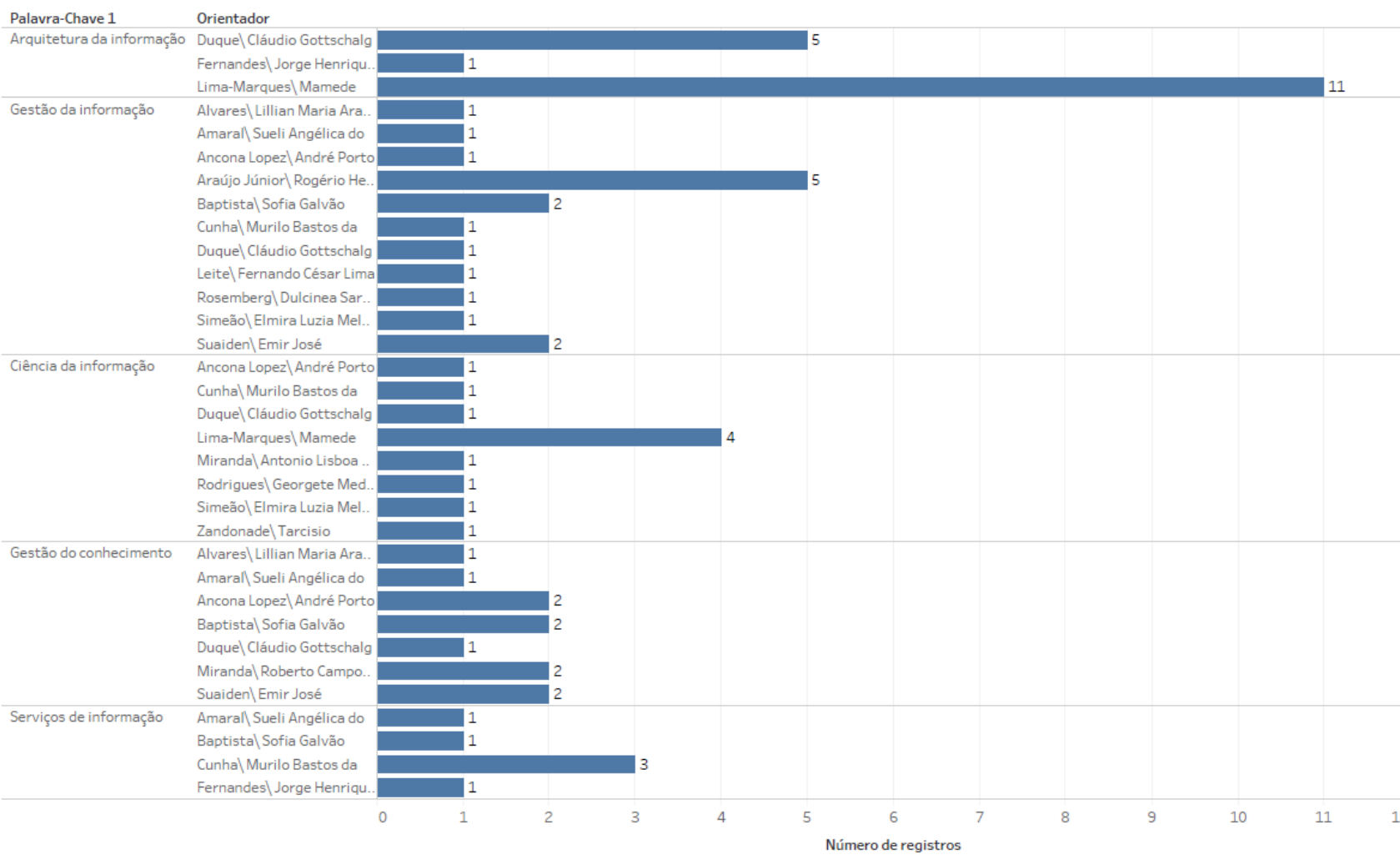

\subsection{Orientadores e palavras-chave}

Outra análise possível, para conhecer melhor os projetos de pesquisa orientados por cada docente, pode ser obtida cruzando o nome do orientador com as linhas de pesquisa. 0 gráfico 10 ilustra esta possibilidade, quando um mesmo orientador pode atuar em várias frentes de pesquisa.

Gráfico 10 - Orientadores e palavras-chave

\begin{tabular}{|c|c|c|c|c|}
\hline Orient.. $\overline{-}$ & Palavra-Chave 1 & Palavra-Chave 2 & Palavra-Chave 3 & \\
\hline \multirow{9}{*}{ 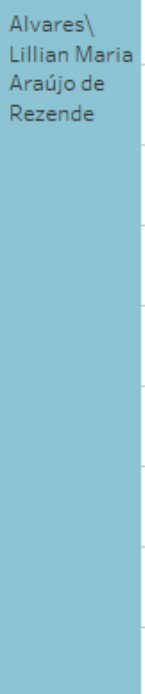 } & Amazônia & Análise de conteúdo & Bibliometria & \\
\hline & Banco do Brasil & $\begin{array}{l}\text { Gestão do } \\
\text { conhecimento }\end{array}$ & Instituições financeiras & \\
\hline & Conhecimento & compartilhamento & Conhecimento tácito & \\
\hline & $\begin{array}{l}\text { Educação } \\
\text { corporativa }\end{array}$ & $\begin{array}{l}\text { Inteligência } \\
\text { organizacional }\end{array}$ & Gestão do conhecimento & \\
\hline & $\begin{array}{l}\text { Gestão da } \\
\text { informação }\end{array}$ & $\begin{array}{l}\text { Instituições de ensino } \\
\text { superior }\end{array}$ & Sistemas de informação & \\
\hline & $\begin{array}{l}\text { Gestão do } \\
\text { conhecimento }\end{array}$ & Análise de redes & Redes sociais & \\
\hline & Gestão escolar & $\begin{array}{l}\text { Sistemas de } \\
\text { informação educacional }\end{array}$ & $\begin{array}{l}\text { Índice de Desenvolvimento } \\
\text { da Educação Básica (Ideb) }\end{array}$ & \\
\hline & Museus & $\begin{array}{l}\text { informaçãoe } \\
\text { documentação }\end{array}$ & Museus & \\
\hline & $\begin{array}{l}\text { Tribunal Superior } \\
\text { do Trabalho }\end{array}$ & Serviços de informação & Estudo de usuários & \\
\hline
\end{tabular}




\section{Considerações finais}

Desde sua criação e, em especial ao longo de sua evolução, o Programa de PósGraduação em Ciência da Informação (PPGCINF) da Universidade de Brasília, demonstra inovação e atualidade de propostas, com áreas de pesquisa dentro do que se consideram as fronteiras da Ciência da Informação, conforme mostram os gráficos de produção acima. Sua produção de dissertações e teses, bem como o comprometimento de seus docentes lhe tem permitido manter um bom nível classificatório entre os cursos de pós-graduação da própria UnB, como também junto ao órgão de controle e credenciamento do Ministério da Educação (MEC/CAPES).

Percebe-se, claramente, que as pesquisas desenvolvidas, ao longo dos anos têm atingido e mantido as abordagens de sua proposta inicial, ou seja, as abordagens sociocultural, a centrada no usuário e a tecnológica, vistas sob o prisma de suas atividades básicas de aquisição, processamento, recuperação e disseminação da informação e evoluído em busca da ampliação da interdisciplinaridade, com linhas de pesquisa que abrangem os campos da aprendizagem, do comportamento, da segurança e da administração, entre outros. Cabe notar o ingresso da Arquivologia e Museologia, em complemento à Biblioteconomia, formando hoje as principais áreas de constituição da pesquisa em Ciência da Informação da UnB.

Com referência ao aspecto sociocultural, no entanto, é importante observar o exponencial crescimento das tecnologias da informação e comunicação, que têm exercido influência soberana sobre organizações e usuários, mudando a cultura social e o comportamento informacional. Este último fator será determinante para novos interesses sociais e culturais, e, portanto, as pesquisas deverão se adequar e, na medida do possível, antecipar-se às suas demandas, utilizando-se também das tecnologias próprias advindas dessa nova realidade (BARABÁSI, 2018) ${ }^{55}$.

No caso da Gestão da Informação, por exemplo, nos novos contextos da web 2.0, 3.0, 4.0, e das redes sociais é importante acompanhar os novos significados dos elementos de seu estudo como valor, qualidade, posse, uso e segurança da informação. Em especial, na seleção e interpretação da informação em contextos específicos, a atividade de análise da informação terá significado especial, assim como se evidencia na análise de informação da presente pesquisa.

\section{Referências}

ALI, T. F. Crescimento: John Dewey e sua contribuição à noção de formação no pensamento pedagógico moderno. Dissertação (mestrado). Florianópolis, SC, Universidade Federal de Santa Catarina, Centro de Ciências da Educação. Programa de Pós Graduação em Educação, 2014.

ALVARES, L. Graduação em Museologia: significados, opções e perspectivas. Museologia \& Interdisciplinaridade; Brasília, v. 1, n. 1, p. 236-250, jan./jul. de 2012.

ALVARES, L. Descoberta de conhecimento na Biblioteca Digital Brasileira de Teses e Dissertações (Relatório de Estágio Pós-Doutoral), Castellón de la Plana, Comunidade

\footnotetext{
55 Já se discute uma nova ciência - a network Science (ciência das redes) - este campo tem um forte caráter computacional, utiliza-se de algoritmos, gestão de bases de dados, mineração de dados e teoria dos grafos (graph theory). Interdisciplinar tem interfaces com a matemática, biologia, ciências sociais e outras. Volta-se para o estudo da difusão da informação em redes complexas. Ver também: http://networksciencebook.com/
} 
Valenciana, Espanha. Escola Superior de Tecnologia i Ciències Experimentals/Departament de Llenguatges i Sistemes Informàtics. Universitat Jaume I, UJI. 2017.

ARAUJO, C. A .A. Arquivologia, Biblioteconomia, Museologia e Ciência da Informação: o diálogo possível. Brasília, DF: Briquet de Lemos / São Paulo: Associação Brasileira de Profissionais da Informação (Abrainfo), 2014.

BARABÁSI, A. L. The formula; the universal laws of success. New York: Little, Brown and Company, 2018.

BARRETO, A. de A. A eficiência técnica e econômica e a viabilidade de produtos e serviços de informação. Ciência da Informação, v. 25, n. 3, p. 1996.

BELKIN, N.; ROBERTSON, S. Information Science and the phenomenon of information. Journal of the American Society for Information Science, v. 34, n. 4, p. 197-204, 1976.

BOELL, S. K. Information: fundamental positions and their implications for information systems research, education and practice. Information and organization, v. 27, p. 1-16, 2017.

BORGES, M.A.G.; BRITO, M. de. (Org.) Criação da Faculdade de Biblioteconomia da UnB: 19621967. Brasília: UnB/FCl, 2013. Disponível em: < http://www.youblisher.com/p/977073-Criacaoda-Faculdade-de-Biblioteconomia-da-UnB-1962-1967 >. Acesso em: 18.10.2018

BOURDIEU, P.; PASSERON, J-C. A reprodução: elementos para uma teoria do sistema de ensino. Lisboa: 1970.

BRAGA, M. O concurso de Brasília: sete projetos para uma capital. São Paulo: Cosac Naify, Imprensa Oficial do Estado, Museu da Casa Brasileira, 2010.

BRASIL. Lei no 3.998, de 15 de dezembro de 1961. Autoriza o Poder Executivo a instituir a Fundação Universidade de Brasília, e dá outras providências. Diário Oficial da União, 15 dez. 1961.

CAITANO, A. O educador revolucionário. Darcy, Revista do jornalismo científico e cultural da Universidade de Brasília, v. 10, p. 12-15, abril e maio de 2012.

CAMPELLO, B. O movimento da competência informacional: uma perspectiva para o letramento informacional. Brasília. Ciência da Informação, v. 32, n. 3, 2003. Disponível em: <http://revista.ibict.br/ciinf/article/view/986/1027>. Acesso em: 14.10.2018.

CAPURRO, R.; HJÖRLAND, B. O conceito de informação. Perspectivas em Ciência da Informação, v. 1 2, n. 1, p. 148-207, jan./abr., 2007.

COSTA, L. Relatório do projeto do Plano Piloto (PPB). In: BRAGA, M. O concurso de Brasília: sete projetos para uma capital. São Paulo: Cosac Naify, Imprensa Oficial do Estado, Museu da Casa Brasileira, 2010. p.164-175.

CUNHA, M. B. da. Abner Lellis Correa Vicentini. In: BORGES, M.A.G.; BRITO, M. de (Org). Criação da Faculdade de Biblioteconomia da UnB: 1962-1967. Brasília: UnB/FCl, 2013. p. 49-72.

DEWEY, J. Democracia e Educação. Trad. Godofredo Rangel e Anísio Teixeira. São Paulo: Companhia Editora Nacional, 1959. 
DIAS, M. A. R. UnB e comunicação nos anos 1970: acordo tácito, repressão e credibilidade acadêmica. Brasília, DF: UnB, 2013.

FERRAZ, I. G. Introdução. In: FERRAZ, I. G. Darcy Ribeiro: utopia. São Paulo: Hedra, 2008. p. 918.

GARCIA, M. L. de A. A informação científica e tecnológica no Brasil. Brasília. Ciência da Informação, v. 9, n. 1-2, p. 41-81, 1980.

GUINCHAT, C.; MENOU, M. Introdução geral às ciências e técnicas da informação e documentação. Brasília: IBICT/CNPq, 1994.

GUYOT, B. Quelques problématiques pour éclairer l'étude de l'information dans les organisations. Sciences de la Société, n. 50-51, p. 129-148, nov 2000.

HAWKINS, D.T. Information Science: Abstracts: tracking the literature of Information Science. Part 1: Definition and Map. Journal of the American Society for Information Science and Technology, v. 52, n. 1, p. 44-53, 2001.

HJÖRLAND, B. Fundamentals of knowledge organization: trends in knowledge organization research. Salamanca: Universidad de Salamanca, 2003.

HOUAISS, A. Dicionário Houaiss da língua portuguesa. Rio de Janeiro: Objetiva, 2001.

KRIEGER, M. G.; FINATO, M. J. B. Introdução à terminologia: teoria e prática. São Paulo: Contexto, 2004.

MALCLÈS, L. N. La bibliographie. Paris: P.U.F., 1973. 128p. Coll Que sais-je?, n. 708.

MIGLIEVICH-RIBEIRO, A. Darcy Ribeiro e UnB: intelectuais, projeto e missão. Ensaio: aval. pol. públ. Educ., Rio de Janeiro, v. 25, n. 96, p. 585-608, jul./set. 2017.

MOTTA, R. P. S. As universidades e o regime militar: cultura política brasileira e a modernização autoritária. Rio de Janeiro: Zahar, 2014.

OTLET, P. Traité de documentation: le livre sur le livre. Bruxelles: Editiones Mundaneum, 1934.

RIBEIRO, D. A Invenção da Universidade de Brasília: 1961-1995. Brasília: Senado Federal, 1995. Carta n. 14.

RIBEIRO, D. (Org.). Universidade de Brasília; projeto de organização, pronunciamento de educadores e cientistas e lei no 3.998 de 15 de dezembro de 1961. Brasília: Editora Universidade de Brasília, 2012.

SALMERON, R. A. A universidade interrompida: Brasília 1964-1965. Brasília, DF: EdUnB, 2012.

SARACEVIC, T. Ciência da Informação; origens, evolução e relações. Perspectivas em Ciência da Informação, v. 1, n. 1, p. 41-62, jan./jun. 1996. 
SHERA, J. Epistemologia social, semântica geral e biblioteconomia. Ciência da Informação, v. 6, n. 1, p. 9-12, 1977.

TEIXEIRA, A. Plano de construções escolares de Brasília. Revista Brasileira de Estudos Pedagógicos, v. 35, n. 81, p. 195-199, jan./mar. 1961.

UNIVERSIDADE DE BRASÍLIA/Faculdade de Ciência da Informação. Documento norteador da pós-graduação em Ciência da Informação da Universidade de Brasília. Brasília: FCl/UnB, 2010.

UNIVERSIDADE DE BRASÍLIA/Faculdade de Estudos Sociais aplicados/Departamento de Ciência da Informação e Documentação. Biblioteconomia: manual do curso de graduação. Brasília: Universidade de Brasília, 2005.

VICENTINI, A. L. C. Informática. Coimbra, Portugal, Cadernos de Biblioteconomia, Arquivística e Documentação, 1968.

ZURKOWSKY, P, G. The information service environment; relationship and priorities. Related Paper n.5, National Commission on Libraries and Information Science, Washington, D.C. National Program for Library and Information Services, Nov. 1974. 